Why, When and How Much to Entertain Consumers in Advertisements?

A Web-based Facial Tracking Field Study

Thales Teixeira ${ }^{1}$, Rosalind Picard, ${ }^{2}$ and Rana el Kaliouby ${ }^{3}$

- December 2013 -

1 Assistant Professor, Harvard Business School, Harvard University, Morgan 165, Soldiers Field Rd, Boston, MA 02163, USA, Tel. (617) 495-6125, tteixeira@hbs.edu.

2 Professor of Media Arts and Sciences, Media Lab, Massachusetts Institute of Technology, E14-374G, 75 Amherst St, Cambridge, MA, 02139, USA, Tel. (617) 253-0611, picard@media.mit.edu.

Co-founder, Chairman, and Chief Scientist, Affectiva Inc. Waltham, MA, Tel: (781) 9963037

3 Chief Technology Officer and Co-founder, Affectiva Inc. Waltham, MA, Tel: (781) 9963037, kaliouby@affectiva.com.

The authors would like to thank Rich Sadowsky for customizing the web-based facial tracking system for this research. The authors would also like to thank Andy Dreisch and Brent Sapiro of Affectiva, Inc. for helping collect the data. The first author would like to thank John Deighton, Rohit Deshpande, Michael Norton and Rik Pieters for their valuable suggestions regarding an earlier version of this paper, and especially to Anissa Mak and Sumit Malic for valuable research assistantship. The usual disclaimer regarding responsibility for mistakes applies. 


\begin{abstract}
The presence of positive entertainment (e.g., visual imagery, upbeat music, humor) in TV advertisements can make them more attractive and persuasive. However, little is known about the downsides of using too much entertainment. This research focuses on why, when, and how much to entertain consumers in TV advertisements. We collected data in a large-scale field study using 82 ads with various levels of entertainment shown to 178 consumers in their homes and workplaces. Using a novel web-based face tracking system, we continuously measure consumers' smile responses, and their viewing interest and purchase intent. A simultaneous Bayesian Hierarchical model is estimated to assess how different levels of entertainment affect purchases by endogenizing viewing interest. We find that entertainment has an inverted U-shape relationship with purchase intent. Importantly, we separate entertainment into that which comes before the brand versus that which comes after, and find that the former is positively associated with purchase intent while the latter is not.
\end{abstract}

Keywords: Hierarchical Bayes, advertising, entertainment, facial tracking, smile measurement 
"Good copywriters have always resisted the temptation to entertain...The purpose of a commercial is not to entertain the viewer, but to sell him.” David Ogilvy in Confessions of an Advertising Man, 1963

“... the latest wave of factor-analysis reveals that [entertaining with] humor can now sell."

David Ogilvy in Ogilvy on Advertising, 1985

Entertainment is an important and pervasive element of television ads. Most ads today have at least one form of content used to entertain the consumer, such as humor, fun stories, or upbeat music. Recently, advertisers have been attempting to create ads with ever increasing levels of entertainment (CNN Money 2007). Examples are the highly entertaining Super Bowl and viral ads. This trend is not necessarily bad for brand advertisers, as entertainment in ads is considered to be an effective method of capturing and retaining viewers' attention. However, the ultimate goal of ads is to persuade consumers toward a product, service, or idea. The goals of increasing an ad's attractiveness and persuasiveness are generally compatible. But what if too much entertainment can increase interest for the ad and, at the same time, be detrimental to persuasion?

Prior research on this topic has focused on identifying what is versus is not entertaining (Tellis 1998) and on how to use entertainment (Armstrong 2010). The effects of entertainment on intermediary measures of ad effectiveness have also been studied, including capturing viewers’ attention (Woltman Elpers et al. 2003), improving attitudes toward the brand (Mitchell and Olson 1981) and, in the special case of creative content, directly influencing sales, purchase intentions and other measures of ad effectiveness (Kover et al. 1995, Reinartz and Saffert. 2013, Smith et al. 2007, Yang and Smith 2009). Prior studies have examined less the downside of evoking positively experienced entertainment, i.e., that which is favorably received by viewers but can be potentially problematic for the advertiser, as we explain later. If this is the case, the challenge for the advertiser is to determine the appropriate balance of entertainment to use in ads. 
We contribute to the literature on entertainment in advertising by (i) showing the downside of using too much entertainment in ads, by (ii) identifying the conditions under which advertisers, based on their goal to generate awareness, interest or purchases, should use more or less entertainment and, lastly, by (iii) demonstrating the order effects between entertainment and first-brand exposure, which we show to ultimately impact entertainment's persuasiveness.

We conducted a large-scale field study by measuring entertainment ${ }^{1}$ more naturally, in a web setting, and address three important questions. One, is there such a thing as having too much positive entertainment in ads? If too much positive entertainment can have detrimental persuasion effects in ads, and we find it does, then, two, it becomes important to understand how much entertaining content should be used. We find evidence that as much as a quarter of TV ads have passed the optimal level by dedicating too much of the ad time to entertain the consumer. Three, does it matter when during the ad the entertainment occurs? We find that where entertainment is placed relative to the brand's first appearance has significant impact on the consumer's intent to purchase the brand.

This research also provides new conceptual understanding of how the level of entertainment in an ad is related to its attractiveness and persuasiveness in increasing purchases. To do so, we propose a new individual-specific measure to identify whether the viewer associates the entertainment experienced in the ad with the brand based on the order of its presentation relative to the brand. We define pre-brand-associated entertainment (preBAE) as that which precedes the first presentation of the brand and post-brand-associated entertainment (postBAE) as that which follows the first presentation of the brand. These types of entertainment are predicted to have different roles regarding the ad's attractiveness and its persuasiveness.

In order to test our predictions, we collected consumer reactions, outside of a lab, while

\footnotetext{
${ }^{1}$ We are agnostic about identifying exactly what is the source of the entertainment used in the ads studied here.
} 
viewing video ads. We measured viewer's expressed entertainment levels by filming their facial reactions to measure smile intensity, viewer's interest in the ad as quantified by whether they watch the ad until the end ${ }^{2}$, and viewer's intent to purchase the brand. We repeated this with 178 consumers exposed in the field to a series of ads from a random sample of 82 ads representing 35 brands in three product categories (beverages, alcohol, and confectionary). These data permit us to assess the impact of different levels of entertainment on the ad's attractiveness, as measured by whether they view the ad or skip, and its persuasiveness, by their purchase intentions. Our focus is only on "positive entertainment," i.e., that which induces immediate positive reactions such as grins, smiles, and laughter (henceforth referred to simply as “entertainment”). We do not focus on mild entertainment that causes no facial reactions nor on entertainment such as suspense or horror, which can cause negative facial reactions. To our knowledge, this is the first largescale field study of its kind to remotely capture consumers’ facial reactions over the web.

We model this data using a mixed Hierarchical Bayesian model to account for observed and unobserved individual and ad content heterogeneity. We endogenize viewing interest, as this can be directly affected by the entertainment in ads. In assessing the impact of entertainment on purchase, we control for other factors such as prior purchase consideration, prior exposure to the ad, and involvement with the category.

Among our findings is that entertainment works via two routes: it impacts purchase intentions directly, through a persuasion mechanism, and, indirectly, by increasing the ad's attractiveness. The latter is positive and monotonic. The more entertainment in the ad, the more it is viewed. The former is inverted-U shaped. Increasing entertainment directly increases the ad's persuasiveness up to a certain point, but decreases it thereafter. Other robustness checks reveal

\footnotetext{
${ }^{2}$ We also considered using amount of viewing time as the measure of interest for the ad but, due to variations in people's evaluation or reaction time, it is not clear that a participant who watched a 30-second ad for 15 seconds versus 10 seconds is more interested in it. We also find no strong relation between timing and interest in our data.
} 
that this pattern occurs for a major group of individuals in our data. In addition, we find that the optimal level of entertainment in ads depends on its location relative to the first appearance of the brand. Entertainment evoked before the consumer is aware of the brand advertised slightly reduces purchase intent. In this case, entertainment has a competing effect with brand persuasion. Conversely, entertainment evoked after the consumer sees the brand increases purchase intent. In this case, entertainment has a cooperating effect with brand persuasion.

An implication for managers is that the optimal amount of entertainment to impact the top stage of the purchase funnel, e.g., convert awareness to interest, should be higher than that which is optimal for the bottom stage, e.g., convert interest to purchase. Here, managers should jointly balance the level and location of entertainment with the brand's first appearance.

In the remainder of this paper, we review the literature on the different roles of entertainment in ads. We then explain how the data for estimating the empirical model is collected and follow with specifying the model used. Lastly, we present results and provide managerial recommendations regarding the role of the level and location of entertainment in ads.

\section{THE ROLE OF ENTERTAINMENT IN ADVERTISING}

Prior research broadly distinguishes between two types of advertising content, entertainment and information (Woltman Elpers et al. 2003). These authors define the amount of entertainment in an ad as the extent to which it contains "entertaining, warm, and playful material that makes the commercial pleasant to watch.” Other authors have defined entertainment in ads as content that is lively, amusing, imaginative, or clever (Aaker and Bruzzone 1981). Common among these terms is the notion of emotional gratification that viewers experience, even if they have no intention of purchasing the advertised product. In other 
words, the ad itself is attractive and induces pleasure throughout its viewing. We define entertainment by the union of both of these definitions and operationalize it by measuring positively expressed entertainment. See Table 1 for examples present in the ads chosen.

Information in commercials, on the other hand, is defined by the presence of cues about the product or advertiser such as the price, quality, performance, contents, availability, offers, etc. (see Resnik and Stern 1977). Information content in ads can increase their attractiveness and persuasiveness. Much of the advertising literature has claimed that the fundamental role of advertising is to communicate this type of information and that creativity and the entertainment aspect of the ad is used mainly to enhance the communication process (e.g., see Ang et al. 2007).

[Insert Table 1 about here]

Most prior measurements of entertainment determine the amount of entertainment present either via self-report using sliding scales or using independent judges (Baumgartner et al. 1997; Woltman Elpers et al. 2004). While the former is also an individual-specific measure, it is cognitively mediated and may interfere with attention to the ad. The use of content coding by judges does not easily allow for idiosyncratic entertainment to be measured differently across consumers. We take a different approach to measuring entertainment. Instead of relying on selfreported feelings, we use a behavioral measure that captures subtle or stronger smiling expressions (e.g., grins, smiles, or laughter) elicited when entertainment such as humor, visual imagery, upbeat music, or fun stories is shown. Next, we elaborate on and conjecture about the differential role of entertainment along two key stages of a consumer's purchase funnel.

\section{Entertainment and ad attractiveness}

There is evidence that entertainment in advertising impacts ad effectiveness differently at different stages of the consumer's purchase funnel. According to Tellis (2004, p. 29), at the 
initial stages, "lack of interest and active avoidance of advertising are the major reasons why advertising tends not to be effective.” Therefore, entertainment first should capture the viewer's interest. Prior research indeed has found a direct association between the amount of entertainment and consumers' viewing time of TV commercials (Woltman Elpers et al. 2003).

Entertainment also breaks through the clutter, particularly if the ad is creative. Research has shown that creative ads get more attention and stand out (Ang et al. 2007, Smith et al. 2007).

\section{Entertainment and ad persuasiveness}

Apart from capturing attention and evoking interest, various forms of entertainment have also been shown to facilitate persuasion. For one, with more viewing interest, persuasion becomes more likely. Prior research has indeed shown that sustained attention mediates the effect of advertising exposure on sales (Chandon et al. 2007). In addition to this indirect effect, to the extent that it is well-received by the viewer, entertainment is said to have a direct impact on purchase intent as it evokes affect from positive attitudes toward the ad (MacKenzie et al. 1986). Another strand of advertising literature has shown the relationship between entertaining content, when positively experienced, and brand-related benefits. To the extent that humorous entertainment is a representative class of entertainment, prior research has shown that humor acts by putting the audience in a good mood, reducing their resistance to being persuaded and, through a process of conditioning, transfers positive associations between the ad and the brand (for summary, see Eisend 2011; Janiszewski and Warlop 1993). Research on creative content has also shown a link between the positive affect evoked by this other form of often entertaining content and more favorable brand evaluations and purchase intentions (Keller 1987; Yang and Smith 2009). In sum, most research has focused on the upside of using entertainment.

Among the downsides of using humorous and other entertainment in ads are instances 
when it is not perceived in a positive manner, thereby generating a negative consumer reaction. This is the case of boring, stale, or offensive humor, or that which reduces credibility (Belch and Belch 2007). Our work focuses on entertainment that is positively expressed, e.g., generates a smile. This entertainment is routinely used in ads for the three product categories in our study.

There is little prior research, however, on the downside to advertisers of extensively using entertainment that viewers experience as positive, for the purposes of persuasion. Two exceptions are worth noting. One is when positive entertainment distracts the viewer from the brand and its attributes, thereby harming comprehension. Mitchel and Olsen (1981) explain that an individual can pay close attention to an advertisement for its entertainment value and this may detract her from actively processing brand-relevant associations. The other notable exception is Sternthal and Craig (1973), who argue that the proper development of entertaining content such as humor requires much of the available ad time that might better be used in developing product or brand information. Entertainment, they argue, can simply overcrowd the product message.

In sum, prior research on entertainment and humor has shown beneficial effects of ad entertainment on interest, as well as on persuasion from using "appropriate” entertainment, and detrimental impacts from using "inappropriate" entertainment. We propose that entertainment that engages viewing and elicits smiles, what might be considered "appropriate" entertainment, may also have detrimental effects, particularly if used excessively or in the wrong place. We shed light on this issue by focusing on the dual purpose of ads: to be attractive and persuasive. This will guide the assessment of the optimal level of entertainment to use. Further, prior studies using entertaining ads were "mostly performed in controlled laboratory settings, are only mildly amusing, and the effects may therefore differ from the effects of real world advertisements” (Eisend 2009, p. 193). We bring new understanding of the issue by gathering data from real- 
world viewing of a large sample of ads evoking various levels of entertainment and creativity.

\section{Entertainment and creativity}

There are cognitive and affective effects from creativity in ads. Creativity has been defined as "the extent to which an ad contains brand or executional elements that are different, novel, unusual, original, unique, etc.” (Smith et al. 2007). The extant literature has been clear to note that creativity is not conceptually similar to entertainment, although consumers oftentimes confound the two. Smith et al. (2007) has shown that creative ads get more attention but only certain dimensions of creativity, e.g., divergence and relevance, are direct explainers of purchase intent. Others have found that creative ads directly affect purchase intentions by making consumers curious about the brand or product claims (Yang and Smith 2009). The vast majority of research in creativity has found either a positive or a null effect of some element of creativity in ads. Reinartz and Saffert (2013) find that certain types of more creative campaigns are more effective in influencing purchasing behavior, also arguing that in some categories, such as cola beverages, due to its overuse, higher usage of creativity in ads might not increase sales. In sum, to study the impact of different levels of entertainment one should control for creativity levels.

\section{Predictions}

In order to assess the role of an ad's entertainment level on its effectiveness, we need to account for the two major routes by which entertainment can influence the consumer's intent to purchase the brand. Based on prior literature, entertainment can influence purchase both directly, by increasing the ad's persuasiveness, and indirectly, by increasing the ad's attractiveness. The literature thus suggests a dual-route model, which is depicted in Figure 1, side (A). Endogenizing interest for the ad permits us to measure both the direct and indirect effect of entertainment on purchase intent to later characterize the optimal level of entertainment in ads. As depicted, we do 
not assume that contemporaneous purchase decisions drives interest and explain how to control for past purchases and past exposure to entertaining content in the modeling section. Given the prior findings in the literature, our predictions are as follows:

P1: Controlling for ad length, higher levels of positive entertainment in ads increases the intent to purchase the brand indirectly by (a) increasing the viewers' interest in viewing the ad and (b) higher interest for the ad increases purchase intent.

These effects should be monotonic. More entertainment should lead to more viewing interest, and this to higher purchase likelihood. On the other hand, the direct impact of entertainment levels on purchase likelihood should have a non-monotonic relationship, controlling for ad length, because at some point a high level of entertainment starts to "crowd out" (Sternthal and Craig 1973) or interfere with (Mitchel and Olsen 1981) the brand and product-related messages in the ad. Thus, we predict that:

P2: Controlling for ad length, higher levels of positive entertainment in ads increases the intent to purchase the brand directly up to a certain point, after which entertainment level decreases intent to purchase the brand.

To test these predictions, two broad approaches can be taken. For one, we could select a few ads to manipulate the level of entertainment in them by adding or deleting scenes. The benefit of exogenous manipulation is a greater chance of attributing causality, although causality can still not be proven because the manipulations may change other aspects of the experience as well. The downsides are that the manipulations would presume to be increasing or decreasing the entertainment, but we know that entertainment is largely what is perceived as entertaining by a viewer; better would be to objectively measure how much each viewer is entertained by each ad. Also, manipulations we make of the ads would no longer be real ads, and thus any findings 
would be somewhat "academic" compared to using real-world ads. Lastly, the findings may only apply to a small range of the entertainment scale versus that which is evoked by real ads in the marketplace. A second approach is to randomly choose a large sample of real-world ads covering a variety of levels of entertainment and measure the level of entertainment in each one. The benefit is generalizability to other ads in the market place and findings that apply to real-world advertising experiences. The downside is that there could be other confounds co-occurring with entertainment levels that might impact its effectiveness. Given the research questions, we opted for the latter approach and attempted to mitigate its downside by collecting other measures to reduce the impact of observable confounds. We also use Bayesian modeling techniques to control for unobservable confounds. Next, we describe the field study design.

[Insert Figure 1 about here]

\section{FIELD DATA COLLECTION PROCEDURE}

Facial expressions associated with entertainment (i.e., smiling) during exposure to a series of television commercials were recorded remotely using participants’ webcams in a web-based field study. Viewing interest for the ad and intent to purchase the brand were also measured.

\section{Participants and Stimuli}

Two hundred and seventy five participants (mean age 26, range 21 to +50 years, $38 \%$ male), composed of both students and non-students, participated in return for a \$5 Amazon gift card. To test the system, the first 38 participants were invited to do the study in the lab and received an additional \$10. Stimuli were a random sample of TV commercials chosen from AdForum, a major repository for advertisements used by professionals in advertising and containing more than 120,000 campaigns. Three product categories-confectionary, beverages, and alcoholic beverages - were chosen for external validity, based on their historical use of positive 
entertainment in advertising (Armstrong 2010). Further, prior research has found that ad attitudes associated with entertaining images are transferred to brand attitudes to some extent in predominantly hedonic and medium involvement categories such as beverages and snacks (Janiszewski and Warlop 1993) and alcoholic beverages (Voss et al. 2003). Approximately 40 ads were initially chosen from each category and this set was reduced to those ads evaluated by an independent judge as having at least some presence of positive entertainment content (as per definitions on page 5), being shorter than 90 seconds, and no more than two years old. The judge was required to assess if the ad's intention was to be entertaining, versus purely informative (e.g., corporate messages), not the extent of the entertainment in the ads. All ads were then reviewed by an author for compliance. The final list of confectionary ads was made up of 24 commercials from eight brands (Cadbury, Dentyne, M\&Ms, Skittles, Snickers, Starburst, Stride and Trident). Thirty-five ads representing 15 brands were taken from the beverage category (Coca Cola, Coke Zero, Cravendale, Cumberland Farms, Diet Pepsi, Glaceau Vitamin Water, Lipton Brisk, Mountain Dew, Muscle Milk, Pepsi, Pepsi MAX, Red Bull, Snapple, Sobe and Sun Drop). The alcoholic beverage category consisted of 23 ads from seven brands (Bud Light, Bud Light Lime, Budweiser, Captain Morgan, Dos Equis, Made in Milan and Ten Cane Rum).

Each participant was exposed to a sequence of 20 out of the 82 TV commercials in a randomized order and was only exposed to one ad for each brand. The selection of which 20 ads each participant viewed was based on a random sample with the constraints that there were only one ad for each brand: one ad for each alcohol brand, one for each confectionary brand, but only one ad for five of 15 beverage brands were used. The purpose of this was to reduce the duration of the study yet still allow for ads of brands in the same category to compete with each other. Except for two brands, all other brands had between two and 10 different ad executions each, so 
as to reduce the influence of a specific creative on a brand's interest or purchase. The full list of ads is provided in Appendix 1. Controlling ad assignment is used to measure variations in entertainment across ads, versus direct manipulation of entertainment level within ads.

\section{Data Collection}

An email was sent to a panel of participants who had registered to participate in online studies. The cover story was "to understand consumer evaluation to video ads." The conditions for participation were to be over 21 years old, have low to moderate amounts of facial hair (mustache or beard) so that their smiles could be detected, and have access to a computer with an Internet connection and a webcam. They were explicitly told that, for compliance assessment reasons, their facial images would be captured and that their compensation relied upon the quality of this data (i.e., appropriate lighting condition and framing of the face in the video). Upon acceptance, participants clicked on the survey link, and were led to the survey page containing the ads. Before the videos, participants were required to answer questions about their prior familiarity with the brand, brand-entertainment associations, and consideration of brands to purchase in the three categories of interest. These questions were asked for all the brands that a participant would be exposed to as well as for a set of other comparable brands in each category for which they would not see ads. After this pre-survey, participants were shown the 20 ads randomly chosen for them in a random sequence. For each ad they were told that they could skip the ad at any point in time by using the space bar. After full or partial view of each ad, they were asked about their familiarity with the ad and their intent to purchase the brand. After all of the ads were shown, participants were asked about the degree to which they felt uncomfortable being filmed, the degree to which their ad and brand choices were different from usual, ${ }^{3}$ their level of

\footnotetext{
${ }^{3}$ At the end of the study, participants reported low levels of feeling uncomfortable being filmed, mean of 2.1 (s.d. 1.2), and of choosing differently from usual, mean of 1.5 (s.d. 0.9), on a 5 point scale.
} 
extraversion, their location and type of internet connection used, and their age and gender. See exact wording in Table 2. The entire study lasted between 25 and 45 minutes.

[Insert Table 2 about here]

\section{Measures Collected}

Purchase Intention. The main dependent variable of interest is the participant's likelihood of purchasing the brand, measured on an 11-point scale anchored by "not at all likely" to "very likely” (similar to Keller 1987). Prior research has argued that for low involvement categories, intentions represent established attitudes to some extent (Fitzsimons and Morwitz 1996).

Viewing Interest. The endogenous dependent variable of focus is viewing interest, whether a participant chooses to fully view a particular video or to press the skip button $(1=$ interested, 0 = not interested), similar in spirit to Pieters and Wedel (2012). This variable measures interest (or lack thereof) for the ad, not for the brand.

Across ads, average viewing interest (completed views) was $81 \%$ (s.d. 39\%), which is similar to the percentage of ads viewed relative to TV content for channels targeting this demographic such as MTV (83\%), E! (83\%) and Bravo (84\%) (Advertising Age 2008). Purchase intent was on average 4.4 (s.d. 2.9) on an 11-point scale. Table 3 provides other statistics.

[Insert Table 3 about here] [Insert Figure 2 about here]

Entertainment level. Facial expression footage from each participant was collected by means of each participant's webcam. This approach unobtrusively captured facial expressions such as smiles without significantly impacting viewers' decisions to view or cease viewing. The facial videos are streamed in real time to a server where they are processed frame by frame using facial emotion analysis software. The software works by finding the main facial features on the face (e.g., location of the eyes, lips, and nose) and then tracking how facial regions such as the 
mouth change in shape to capture facial actions (e.g., smile). The output of the system is a probability measure associated with the intensity of expressed entertainment such as grins, smiles, or laughter. Since it is straining for people to keep smiling and laughing when they are not entertained anymore, this measure frequently returns to a zero baseline, thus avoiding the common spillover effects associated with other moment-to-moment measures such as dial, warmth, and other sliding self-report monitors (Baumgartner et al. 1997). Facial analyses were available approximately fourteen times per second. The "smile classifier" was validated on other datasets collected over the web and similar in nature to ours with accuracy over $90 \%$ (McDuff et al. 2013). For additional details on how the image-based measurement and classification algorithm work see McDuff et al. (2012). The entertainment measured in this study does not include content for which people might react differently than via smiles, e.g., violent, horror or sexual content. Average entertainment expressed across the 82 ads was $23.3 \%$ (s.d. $15.9 \%$ ) on a 0 to $100 \%$ intensity scale. For ad-specific viewing and entertainment measures, see Appendix 1.

Smile detection technology based on facial expressions tracking is becoming more prevalent and reliable. Previous research in marketing has used facial tracking to assess the dynamic role of joy and surprise on engagement to Internet video ads using a similar technology in a lab setting (Teixeira et al. 2012). McDuff et al. (2012) conducted the first large-scale online ad study measuring facial expressions in a naturalistic setting. Their test showed a significant association between the smile intensity of viewers and how much they liked three entertaining ads. Ours is the first advertising study to use this new facial analysis technology in a real-world online setting, relating individual facial responses to interest and purchase intent.

During a period of four months, we collected 4,479 viewing instances from 275 consumers. Each instance was randomly assigned; thus, order of exposure was controlled. For 
$22 \%$ of these instances, the system's algorithm was not able to calibrate, generally due to dark complexions, poor lighting, webcam malfunction or the image of the face being obstructed in some form. See Figure 2 for a random sample of publicly available snapshots of the kinds of videos we captured. We assume that not including this data, due to technical issues such as home illumination angle, does not bias our results in any major way as these unobserved responses are not likely to correlate with our dependent measures. As for the other measures collected from this group, $\mathrm{T}$ tests did not reveal any significant differences between the averages for the group included versus excluded. As far as their location, $76 \%$ of participants reported being at home, $2 \%$ at work, and $22 \%$ in another location. To pilot the system, the data for the first 38 participants were recorded in a lab. We tested our findings with and without these participants and none of the main findings were qualitatively altered. There were 178 people in the final data.

Control variables. Via a questionnaire, we assessed prior familiarity with the ad, age and gender for each participant, since prior research has shown their influence on attention (Teixeira et al. 2010). Prior familiarity, asked after each ad, was 13.7\%. Prior (before the ads were shown) brand consideration was also collected. It is used to control for the role of past purchases on current ad viewing and brand purchasing decisions. Participants considered buying the advertised brand in $24.6 \%$ of the cases before seeing any ads. Prior perception of a brand's fun or entertaining nature was also collected and is used to control for the role of past entertainment on current ad viewing decisions. Participants judged the brands to be medium entertaining, 3.3 on a 5-point scale (s.d. of 1.2). We also collected self-report extraversion measures using a 5-point scale anchored by "Not at all" to "Extremely" to control for the possibility that extraverted consumers are more likely to express entertainment facially (Pervin and John 1999). Further, to control for variations in involvement levels, which affect interest (Tellis 1998, p.121-2), both 
across consumers and across the three product categories studied, we collect category frequency, interest and knowledge measures using 5-point scales anchored by "Not at all” to "Very." Category measures were used as opposed to brand-specific involvement levels since the latter approach would require asking 51 additional questions to each participant, greatly increasing response fatigue.

Ad coded variables. A subset of variables used was measured by using professional coders who work for ad agencies. Although some have argued for using consumers (Ang. et al. 2007) others argue for professional coders over amateur consumers to judge creativity as the consumers tend to overly focus on the entertainment execution attributes of ads (West et al. 2008), a construct we already measure via facial expressions. In addition, for coding ad executions, White and Smith (2001) have argued that "training and experience in advertising becomes a key factor.” The level of creativity of each ad was also coded using 18 expert raters using three 7-point Likert items measuring creativeness, award winning and inventiveness (Cronbach $\alpha=0.90$, intercorrelation range $=\{0.74,0.82\}$ ), adapted from Smith et al.’s (2007) global measures of overall creativity. The adaptation uses the instructions "Using your own subjective definition of creativity assess...,” as recommended by Amabile (1982) when using expert coders in the Consensual Assessment Technique. Similarly, the level of information content in ads was coded by these same experts who judged the presence or absence of 12 cues of product or brand information in the ads as well as its overall informativeness using a 7-point scale adapted from Resnik and Stern 1977. These two items were averaged across raters and items to form a measure of information for each ad (Cronbach $\alpha=0.67$, intercorrelation=0.54). For more details on the ad coding procedure, questions used, summary statistics and reliability, see Online Appendix 2. Lastly, the length of the ad as well as the time to first appearance of the 
brand, previously shown to influence ad viewing time and incidence, was assessed via content analysis (Teixeira et al. 2010). Another independent coder reviewed all the ads and collected these measures. One of the authors checked a subsample of $15 \%$ of ads for accuracy and deemed the coding to be accurate. For comparison, in Table 3 we separate out the average amount of entertainment expressed by the consumer before (pre-brand) and after (post-brand) exposure to the brand image for the first time in the ad. Note that only a slightly higher average entertainment level is expressed after the brand appears for the first time than before (24\% versus $21 \%$ ).

[Insert Figure 3 about here]

As initial evidence for or against predictions P1 and P2, in Figure 3 we plot the average viewing interest and purchase intent by the decile of the average intensity level of entertainment expressed across all observations (ad $\times$ participant). It shows an increasing relationship between entertainment and interest, and an inverted-U shape between entertainment and purchase intent. Only seven of 82 ads are in the ninth and tenth deciles, wherein purchase intent is appreciably lower, but it represents $20 \%$ of the data, by definition. Yet, this analysis does not take into account other important factors, among them the indirect influence of entertainment on purchase intent via increasing an ad's attractiveness, which requires a model to be appropriately examined.

\section{MODEL}

We model the effect of the level of entertainment expressed by each individual over the course of ads on two key stages in the consumers' purchase funnel, namely, interest and purchase. It is important to assess and control for the indirect impact of entertainment on purchase intentions via increased interest for the ad. Therefore, in estimating the effect of entertainment on each stage, we endogenize interest and estimate both consumer decisions simultaneously. 
We define a random utility model for each of the purchase funnel decisions, linking their latent utilities to the level of entertainment in ads and to relevant control variables. $\mathrm{y}^{\mathrm{I}}$ is the utility associated with interest in fully viewing the ad, a binary choice. $\mathrm{y}^{\mathrm{p}}$ is the utility associated with purchasing likelihood for the advertised brand. To test for the direct effects, we linearly associate entertainment expressed with each utility as well as the squared level of entertainment to test for conjectured non-linear effects. To capture heterogeneity, each utility is associated with an individual and ad/brand-specific baseline $\alpha$. In each decision, we also control for categoryspecific influences, namely frequency of purchase, interest and knowledge. Lastly, the expected indirect effect of entertainment on purchase intent via increasing interest for the ad is captured by endogenizing the utility associated with interest. Let $i$ be individual and $a$ be advertisement indexes, we jointly write the top-level equations for the two decision stages as:

$$
\begin{gathered}
y_{i a}^{P}=\alpha_{i a}^{P}+\beta_{1} \cdot \text { Entertainment }_{i a}+\beta_{2} \cdot \text { Entertainment }_{i a}^{2}+\beta_{3} y_{i a}^{I}+\mathrm{B}^{P} X_{i a}+\varepsilon_{i a}^{P} \\
y_{i a}^{I}=\alpha_{i a}^{I}+\beta_{4} \cdot \text { Entertainment }_{i a}+\beta_{5} \cdot \text { Entertainment }_{i a}^{2}+\beta_{6} z_{i a}+\mathrm{B}^{I} X_{i a}+\varepsilon_{i a}^{I} \\
\varepsilon_{i a}=\left[\varepsilon_{i a}^{I}, \varepsilon_{i a}^{P}\right]=N_{2}\left(\left[\begin{array}{l}
0 \\
0
\end{array}\right],\left[\begin{array}{cc}
\sigma_{I}^{2}=1 & \sigma_{I P} \\
\sigma_{P I} & \sigma_{P}^{2}
\end{array}\right]\right),
\end{gathered}
$$

where I stands for Interest-related and P stands for Purchase-related effects. $\boldsymbol{\varepsilon}$ is composed of correlated errors and the variance of the error associated with viewing interest is constrained to one for identifiability. The X matrix is made up of the ad's level of information and creativity, the product category variables (knowledge, interest and frequency of purchase) and prior (e.g., before watching the ad) brand consideration, which might affect both the current decision to view the ad and purchase the advertised brand. The $\mathrm{z}$ vector is composed of prior brand entertainment, to control for the impact that prior exposure to entertaining content might have on an individual's likelihood of viewing ads for that brand. This term does not enter the purchase equation directly as we assume that the impact of any prior exposure to a brand's entertaining 
content will already have been incorporated into the consumer's prior consideration for the brand or influence their current interest in viewing the ad, or both. This structure imposed on the model also provides the necessary condition to satisfy the exclusion restriction for identification reasons (Greene 2008). To account for individual and ad/brand-specific heterogeneity, from observed and unobserved individual and ad attributes, we define $\alpha$ as an additive-separable term with Normally distributed errors as such:

$$
\begin{aligned}
\alpha_{i a}^{s}=\mu_{i}^{s} & +\theta_{a}^{s} \quad s \in\{I, P\} \\
\mu_{i}^{s} & =N\left(W^{s} \mathrm{~K}^{s}, V_{\kappa}^{s}\right) \\
\theta_{a}^{s} & =N\left(Z^{s} \Lambda^{s}, V_{\lambda}^{s}\right)
\end{aligned}
$$

where $\mu$ and $\theta$ are individual and content-specific baseline Interest and Purchase rates, respectively. Each is specified as a normally distributed random effect explained by the sets of covariates in $\mathrm{W}$ and $\mathrm{Z}$, respectively. $\mathrm{W}$ is composed of a participant's age, gender, extraversion level and familiarity with the ad. $\mathrm{Z}$ is composed of the length of the ad and time to first appearance of the brand on-screen.

In sum, Equations 1 and 2 form a mixed-outcome Hierarchical Bayes model with one endogenous variable. Interest is modeled with a probit link function. Given that Purchase intent is positive and right-skewed, we model it with a log-linear link function. Since the correlation between the product category variables is between 0.56 and 0.74 , to avoid collinearity problems we average them out and use a single "Involvement" covariate in both equations. With this exception and a correlation between length of ad and time to first brand appearance of 0.56, all other correlations are less than 0.2.

\section{Model Estimation}

We estimate the model using a Bayesian Monte Carlo Markov Chain (MCMC) sampling methodology with data augmentation for the Interest equation (for details, see Rutz and Trusov 
2011). All priors are standard conjugate diffuse priors. The MCMC chain was run for 3,000 iterations on a total of 3,487 observations. The posterior distributions of the parameters of 2,000 draws were extracted, after a burn-in period of 1,000. Starting values were taken from the maximum likelihood parameter estimates from independent homogeneous Probit and log-linear models. For additional estimation details, see the Online Appendix 1.

\section{RESULTS}

\section{Role of Entertainment in the Consumer Purchase Funnel}

Table 4 summarizes the posterior distributions of the parameters for predicting Viewing Interest and Purchase Intent. The model shows a strong linear effect (mean 0.987) with no significant non-linear effect, showing that as the average level of positive entertainment expressed by viewers increases, their viewing interest, defined by the probability they watch the ad until the end, increases linearly. This supports the theory-based prediction that higher levels of positive entertainment increases interest in viewing the ad (P1a). As for the control covariates, information in the ad is marginally positively related to higher interest in viewing it but creativity is not. Prior brand consideration, prior brand entertainment and involvement with the product category are also associated with a higher interest in viewing the advertised brand. Unfamiliar and shorter ads are more likely to evoke viewing interest. And the significance of age and gender means that older and female viewers are more likely to be interested in viewing the ads. Except for creativity, which was found to be significantly related to re-viewing intentions by Yang and Smith 2009 and we find no significant effect for first time viewing, these results are in accordance with prior findings in the literature.

Regarding the effect of viewing likelihood on the intent to purchase the advertised brand, 
the significance of the endogenous Viewing Interest variable in predicting Purchase Intent (mean 0.220) confirms the indirect route through which positive entertainment influences purchase intent. As predicted, higher interest in viewing the ad leads to increased purchase intent (P1b). Finally, the impact of entertainment on the likelihood of purchasing the advertised brand has a significant linear effect (mean 0.905) and significant non-linear effect (mean -1.014). Figure 4 shows a plot of the added effect of these two terms both for the Interest (left) and Purchase Intent (right) models. Entertainment has an inverted-U relationship with purchase evidencing that $a$ medium level of positive entertainment leads to a higher intent to purchase the advertised brand than low or high levels (P2). Controlling for viewing interest, $23 \%$ of ads have at least one participant in the downward slope portion of the U-curve.

[Insert table 4 about here] [Insert figure 4 about here]

The above findings hold even after we controlled for other ad elements known to influence persuasiveness. As already supported in the literature, our data also supported that highly informative and creative ads are significantly related to Purchase Intent. We also find that prior brand consideration and involvement in a category are significantly related to Purchase Intent even once we endogenously control for viewing interest. As for other controls, familiar ads are more likely to be associated with higher reported purchase intent. Older, male and extraverted consumers are more likely to purchase the brand after seeing the advertisement.

The two key results - viewing interest for ads is monotonically increasing in the intensity of entertainment, and purchase intent has an inverted-U relation to entertainment—are both consistent across the three product categories studied. Thus, we only report aggregate results.

\section{Robustness check}

Past research has shown the risk of attributing average effects found on models estimated 
using aggregated consumer data to individuals (Hutchinson et al. 2000). Under certain conditions, it is possible that a pattern found in an aggregate analysis of people may not be found within any one person in the data. To test if the inverted-U relationship between entertainment and purchase intent is actually an artifact of heterogeneity we re-estimated the purchase model of Equation 1 using latent class models. We used a finite mixture of OLS regressions with either two or five classes, the latter being a result of minimizing the Bayesian Information Criterion. For the two-class model, we found that the largest class, with 57\% of individuals, replicated the inverted-U relationship between entertainment and purchase intent found in our (aggregate) repeated measures model. For the five-class model, we found that two classes, totaling $64 \%$ of the individuals, also showed the inverted-U relationship. Out of these, $40 \%$ were in a group with $\beta_{2}$ significant at 0.05 . The other classes mostly exhibit an increasing relationship between entertainments and purchase intent. Given the current data limitation (i.e., 20 ads/person), it is possible that these participants either possess a linear relationship or were mostly sampled from the upward sloping part of the inverted-U curve. Additional details can be obtained from the authors upon request. In sum, while not all participants may individually exhibit the inverted-U pattern, the finding in the previous section is not simply an artifact of aggregation. This result is novel and provides the first empirical evidence showing that excessive amounts of entertainment can be ineffective for the majority of consumers because it reduces the ad's persuasiveness.

From prior literature, two likely explanations for the inverse relation between high levels of entertainment and purchase intent are that entertainment crowds out the influence of the nonentertainment (i.e., informative) portion of the message or that it reduces the transfer of positive associations to the brand or product advertised. We attempt to tease out the most plausible of these explanations in the following section. 


\section{The Role of Location of Entertainment on Ad Effectiveness}

In advertisements, entertainment is a means to an end. The previous results show that one of these means is to generate interest for the ad, making it more likely to be fully viewed. If executed well, some of this viewing interest will convert into strong intentions to purchase the brand. Yet TV ad space is very limited. If more entertainment than necessary is inserted in ads, there might be less time to communicate other potentially non-entertaining but more persuasive information regarding the product or brand benefits. This “crowding out” hypothesis suggested by Sternthal and Craig (1973) might help explain the inverted-U relationship found between entertainment levels and purchase intent. However, the appropriate test of this hypothesis is whether a higher amount (level $\times$ duration) of entertainment reduces purchase intent. We define two measures: entertainment level is the average intensity expressed by a viewer during a portion of or all of the ad (also used in the previous model), whereas entertainment amount is the sum of intensity of entertainment expressed. Level of entertainment is, by construction, independent from the length of the ad, whereas amount of entertainment can increase with ad length.

An alternative hypothesis is that, apart from piquing interest, entertainment might have an additional role in that it improves brand attitudes via a transfer of positive associations (see Janiszewski and Warlop 1993). The implication is that if entertainment in ads is not brandassociated then it works only as an attention-capturing device and not directly on persuasion, potentially even damaging the latter. Thus, we examine two alternative predictions.

The “associations transfer” hypothesis suggests that higher levels of non-brand-associated entertainment do not improve and may even reduce the positive transfer of associations that impact brand persuasion. The corresponding prediction is:

P3a: Controlling for ad length and viewing interest, the level of non-brand-associated 
entertainment is not positively related to purchase intention.

On the other hand, the "crowding out" hypothesis suggests that higher levels of entertainment require longer ad time to be used for entertainment and this reduces the ad time dedicated to nonentertainment brand persuasion. The corresponding prediction is:

P3b: Controlling for ad length and viewing interest, the amount (level $\times$ duration) of entertainment (brand- and non-brand-associated) is negatively related to purchase intention. In order to test which hypothesis better explains our findings, we attempt to separate the portion of entertainment in each ad that is associated with the brand versus that which is not. Since ad interpretations are idiosyncratic to consumers, we needed an individual-specific measure of the extent to which entertainment is or is not associated to the brand in each ad. Ideally, we would ask each participant how much entertainment they experienced in each ad as well as the portion of which that they associate with the brand and the portion that they don't. This approach has some drawbacks as consumers may not be aware of many attempted associations (Janiszewski and Warlop 1993) or, worse, it may prime them to view these ads in a non-natural manner.

One alternative is to determine the point in each ad when the viewer is most likely to discover what brand is being advertised so as to start making stronger brand associations. We asked an independent coder to determine the first moment of clear brand appearance in each ad. This was defined as the instant of first unobstructed visual presentation of the brand logo, trademark, or pack shot similarly to Teixeira et al. (2010). Then we define any entertainment experienced up to that instant as pre-brand-associated entertainment (preBAE). The viewer unfamiliar with the ad is unlikely to associate the positive feelings evoked form preBAE with the advertised brand. The rest of the entertainment, that which is experienced after the first brand exposure, is defined as postbrand-associated entertainment (postBAE). The viewer can correctly 
make the association with the brand from post BAE. While not perfect, as some might infer the advertiser before seeing the brand (e.g., via audio or other non-brand cues), this classification has some support in the marketing literature. Janiszewski and Warlop (1993) show that the order of exposure of the brand (conditioned stimulus) to "affectively charged events" (conditioning stimulus) influences the association between these two in a classical conditioning sense. They find that affective events appearing in ads after the brand is shown create a much stronger association of meaning to the brand than if shown randomly (before or after). In a similar process, entertainment should create a stronger association with the brand, directly impacting purchase intent, if it comes after the brand than before.

This approach relies on order effects between conditioned and conditioning stimuli to separate high versus low brand-entertainment association. To control for the possibility that some forms of entertainment that come before the brand may be highly associated with the brand, we also chose to have 18 professionals of advertising agencies code the 82 ads for the degree of association between the brand and entertainment. We adapt a composite measure of brand association by averaging four 7-point semantic differential items, correspondence, relationship, fit and consistency (Cronbach alpha of 0.91 and intercorrelations ranging from 0.59 to 0.89) based on prior research as a control (Bryant et al. 1979). For details on the coding procedure, questions used, summary statistics and reliability, see Online Appendix 2.

Before using preBAE and postBAE as a classification for entertainment, we test it by separating the 82 ads by whether the brand first appears in the beginning (first third), middle (second third) or end (last third) of the ad. Similarly, we separate the ads by those with low (first tercile), medium (second tercile) and high (third tercile) levels of entertainment, averaged across ads and viewers. If the location of the brand is related to the effectiveness of entertainment in 
driving purchases, then the highest intent to purchase at different levels of entertainment should be achieved by different locations of the first brand appearance. Indeed, as can be seen in Figure 5, ads with low and medium levels of entertainment are associated with highest intent to purchase when the brand appears in the beginning of the ad versus later on. But for ads with high levels of entertainment, the brand first appearing in the middle of the ad is related to higher purchases. Interestingly, the brand at the end is associated with lower purchase intent for all levels of entertainment in our data. In sum, there seems to be initial empirical support for an interaction between brand location and entertainment level. However, this analysis does not control for important factors discussed in the previous section, as well as the indirect effect of entertainment on purchase via increasing interest for the ad. We account for these issues next.

\section{[Insert Figure 5 about here]}

\section{Results}

We rerun the Purchase Intent model, separating each participant's average level and amount of expressed entertainment into preBAE, if it comes before the first brand exposure, and postBAE, if it comes after. Note that this is an individual-specific measure of brand-entertainment association per ad. As such, the same ad might have higher associations for one viewer but lower for another, depending on the entertainment experienced. For testing proposition 3a, the model is estimated on entertainment levels (average intensity expressed). For testing proposition 3b, we use entertainment amounts (intensity multiplied by duration of experience) where duration of preBAE and postBAE are measured as a proportion of total ad time, to control for ads with different lengths. ${ }^{4}$ Since in $13.7 \%$ of occasions participants had seen the ad before, we disregard that data here. The simultaneous model was re-estimated using the $86.3 \%$ of the data composed

\footnotetext{
${ }^{4}$ In this case, note that if the brand first appears at the very beginning of the ad, then there is no preBAE, and postBAE level and amount coincide. Conversely, if the brand first appears at the very end of the ad, then there is no postBAE, and preBAE level and amount also coincide. In all other cases, these four measures are distinct.
} 
of first-time views. The estimates in Equation 2 did not converge in the MCMC estimation so all covariates in the individual and content-specific baselines were incorporated as covariates in the X matrixes of Equation 1, which then converged. Table 5 shows only the parameter estimates for Purchase Intent as the Viewing Interest estimates do not change much.

We find that, at any level, postBAE helps improve the intent to purchase the advertised brand while preBAE does not help. For the level of entertainment effects (left-most columns of Table 5), postBAE has a significant and linear term (mean 0.698) but not a squared term, which indicates a positive and monotonic relationship with purchase intent. preBAE has the oppositea negative, marginally significant, squared term (mean -0.800) and no appreciable linear term, which indicates a negative relationship with purchase intent. ${ }^{5}$ See the left graph of Figure 6.

For the amount of entertainment effects (right-most columns of Table 5), postBAE and preBAE have significant positive linear effects (mean 0.989 and 1.017), respectively, and both have marginal to significant negative non-linear effects (mean -0.837 and -1.316 ) on purchase intent with appreciable non-monotonicity (Figure 6, right graph). With the exception of information and creativity, non-significant in the level model, all other covariates have effects qualitatively similar to the results of Table 4 . We also find that the expert-coded degree of brandentertainment association is not significantly related to the level or the amount of entertainment.

Jointly, these results suggest that the association transfer hypothesis is the more appropriate explanation for why, at some high level, entertainment is negatively related to purchase intent. In support of Prediction 3a, the left graph in Figure 6 shows that preBAE consistently has a lower impact on purchase intent than does postBAE. And since the experience of the entertainment is approximately the same before and after the brand, it is not the case that advertisers reserve "better" entertainment for the latter part. Second, over all of the ranges of

\footnotetext{
${ }^{5}$ If only a linear term is used, then preBAE becomes marginally significant (mean -0.189, s.d. 0.129).
} 
entertainment observed, preBAE level has either no impact or a decreasing impact on purchase intent. Finally, the higher the postBAE level present in ads, the higher the intent to purchase. Meanwhile, we do not find evidence to confirm the "crowding out" hypothesis (right side of Figure 6) as the amount of entertainment, postBAE or preBAE, is also related to purchase intent in an inverted-U pattern as originally shown (right graph, Figure 4).

[Insert Table 5 about here] [Insert Figure 6 about here]

\section{DISCUSSION}

This research investigates to what extent the average level, total amount (level $\times$ duration) and location of entertainment in ads influences advertising effectiveness at the interest and purchase stages of the consumer's purchase funnel. Although prior studies have separately demonstrated that entertainment has distinct positive effects on ad viewing (Wolman Elpers et al. 2003) and creative content has positive effects on intentions to purchase (Yang and Smith 2009), we show that certain types of entertainment, even when it elicits positive facial reactions, can have detrimental effects on purchase intent, while having beneficial effects on a person's willingness to watch the entire ad. We thus add to this body of knowledge by showing how entertainment operates at these two stages of the purchase funnel.

We find that entertainment plays both a cooperating and a conflicting role, depending on its type (i.e., location in the ad). Entertainment that is strongly associated with the brand (e.g., postBAE) is cooperating, as it acts as a persuasion device both in the interest and purchase stages. Entertainment that is weakly associated with the brand (e.g., preBAE) acts predominantly as an attraction device at the interest stage, thus indirectly cooperating but also directly conflicting with the ultimate goal of increasing purchase intent. The net effect depends on the

level of entertainment in the ad. Thus, we propose a novel model to explain the role of 
entertainment in ads (see Figure 1, side B). This paper shows empirical evidence for this model for three medium-involvement product categories: beverage, confectionary and alcohol products.

Understanding the balance between entertainment and other content in ads and how this balance should be differently optimized for various stages of the purchase funnel is an important step in growing the body of theory concerning how marketing actions affect different stages of the purchase funnel. Our findings also have practical implications for advertising managers as rising competitive clutter in the marketplace has been decreasing attention to ads and causing ad agency creatives to add more entertainment for ads to get noticed (CNN Money 2007). Thus, our model makes substantial contributions to both marketing theory and managerial practice.

\section{Novel Findings and Implications for Creating Advertisements}

We find that, while it is true that entertainment has strictly beneficial effects on viewing interest, there is a downside to using high levels of it when trying to influence purchase intent. In order to understand why a downside of using excessive entertainment occurs, we separated entertainment into two types by location in the ad: pre-brand-associated (preBAE) and post-brand-associated (postBAE), based on whether entertainment is experienced before or after the consumer is fully aware of the brand advertised, respectively. We found that the average level of the former actually has a marginally negative effect, while the level of the latter has a positive effect on purchase intent. In a sense, the positive associations elicited from entertainment do not transfer as effectively to the brand when the brand shows up for the first time after the entertainment (level of preBAE). Interestingly, the amount (level $\times$ duration) of preBAE does not display this detrimental effect. Instead, it follows an inverted-U shape. This suggests that, when it comes to entertaining viewers before they see the advertised brand in the ad, there are more repercussions than just having less ad time to use information to persuade. 
Taken in isolation, these results would suggest that advertisers either not provide any entertainment before the brand is presented in the ad or insert the brand earlier to allow for only postBAE to be present. These are myopic approaches for two reasons. First, we find that any entertainment type has an important positive impact on ad effectiveness via increasing the viewer's interest in watching the ad. Second, past research has found that early presence of the brand increases ad avoidance (Teixeira et al. 2010). Thus attempts to reduce the direct detrimental impact of pre-brand entertainment on purchase intent can also reduce purchase intent indirectly via reducing the ad's attractiveness (i.e., viewing interest).

The answer to the question of how much entertainment to use in ads needs to be jointly determined with (a) where to show the brand for the first time and (b) what is the purpose of the ad. It turns out that maximizing the positive impact of entertainment requires trading off interest for purchase intent. If the indented purpose is solely to induce purchase from consumers highly likely to view the entire ad, then early placement of the brand followed by high levels of (post)entertainment is recommended. This might be the case for very familiar or admired brands. Yet, our data do not indicate that this approach is commonly used in the current ads. There is an almost even balance between the average level of entertainment before (21\%) and after (24\%) the first brand mention, with the brand appearing first, on average, towards the middle of the ad (23 out of 40 sec.). Our results suggest that managers aiming to increase sales should consider both introducing the brand earlier and leaving better quality entertainment for after it is shown. Yet, if the purpose of the ad is to generate awareness and interest, for example for new brands or products, and other marketing tools will be used to trigger purchase, then placing the brand later in the ad (and consequently having more pre-brand entertainment) will be more effective to increase its attractiveness. Lastly, for ads intended to increase interest and purchase, ad 
persuasiveness and attractiveness should be balanced. Our combination of face-tracking data and modeling approach allows managers to asses this for their purposes on a case-by-case basis.

\section{In Vivo Measurement of Advertising Reactions}

In this research, we used a novel methodology to objectively assess the individual-specific moment-by-moment experiences of entertainment in ads by tracking consumers' smiles. While previous research in marketing has used automatic facial expression analysis for similar purposes in a lab setting (see Teixeira et al. 2012), we are the first to conduct a large scale study using facial expressions to capture consumer experiences in vivo. Although not capturing completely unobtrusive viewer behavior, a strength of this approach is the ability to measure more natural consumer responses in the marketplace, where advertising effects regularly operate and interact with the environment. Entertainment in advertising is very idiosyncratic to each individual and testing closer to real-world effects may benefit from a real-time, scalable approach, with high temporal resolution such as ours. Specifically for this research, the ability to capture these reactions moment-by-moment allowed us to tease out postBAE and preBAE for each person and ad, and discover how their impact on persuasion differs. The idiosyncratic nature of our measures provides evidence that advertisers should aim to create ads that are moderately entertaining, on average, for most consumers.

Companies such as $\mathrm{ABC}$ and L'Oréal are also seeing the benefits of using facial expression analysis. One benefit is that visual marketing tools (e.g., for ads, website, packaging) can be evaluated quickly and in a more natural setting. This paper provides a first-step approach for collecting and analyzing this unique type of data with Hierarchical Bayes models.

\section{Caveats, final considerations and future research}

We find that increases in the average level of pre-brand associated entertainment, i.e., that which 
comes before the consumer sees the brand advertised, do not help to increasing purchase intent directly. This is not to say that pre-brand associated content should never be used in ads. It still has the ability to capture viewer attention and interest. Such entertainment may be important to build up the context for the brand to be shown favorably. Another note of caution when implementing these findings is that we do not know exactly the behavioral reason for why the more entertained the viewer feels before knowing the brand advertised, the less their purchase intent goes up. Based on prior literature, we conjecture that it could be due to multiple reasons. Highly entertained viewers might discredit the brand once they discover what is being advertised, either due to disbelief if arguments are used, due to less relevance or meaningfulness of the ad, or due to less empathy if drama is used (Deighton et al. 1989). Viewers might also pay less attention to a message that is associated with the brand once they are already entertained (Mitchell and Olson 1981). Or, in the absence of knowing the advertised brand, viewers can associate the positive entertainment felt to the ad (e.g., "the funny Skittles ad"), as opposed to transferring it to the brand (e.g., "Skittles is a fun brand"). Future research should attempt to tease out which, if any, is (are) most plausible explanations.

Whatever the reason(s) may be, this research suggests that different levels of entertainment should be used in TV ads depending on whether the goal is to maximize interest for the ad (top of funnel) or purchase of the brand (bottom of funnel). Further, while our results control for ad creativity, we do not assess how specific dimensions of creativity (e.g., novelty, meaningfulness, relevance) alter the effectiveness of entertainment at different levels. Future research should also look into this promising issue.

This research also only looks at the effects of entertainment in the short term, of one unique ad exposure, when consumers are forming their preferences closely after watching ads, 
which can be the case for beverages and confectionary. The optimal amount of entertainment to use in ads for long term effects or multiple exposures might be higher than what we report here, as entertaining ads may be more memorable, or lower, as entertaining ads may detract from memorizing brand-related information. The results might also differ depending on the product category (yet, for evidence of the contrary, see Teixeira and Stipp 2013) and on individual characteristics as robustness checks revealed that most, but not all, individuals in our data showed lower intent to purchase at high levels of entertainment. Future research should look into these issues. Other limitations that deserve more research are the lack of programing content and the use of purchase intent versus actual purchase. Despite this, a strength of our method was that we still allowed for viewers to avoid watching ads that they would not want to see on a daily basis, and to be influenced by ads of competing brands. Lastly, this paper is agnostic regarding the kind of content that entertains, yet we don't assume it does not matter. For example, Teixeira and Stipp (2013) find significant differences between humor and other forms of entertainment.

As creative professionals in advertising agencies increasingly compete with one another for the funniest Super Bowl ad or the most entertaining viral ad, this "race for being most entertaining" might come at the expense of the persuasiveness of the ad in driving sales. It is up to the brand manager to curb this race for entertainment for entertainment's sake, unless the only goal is to heighten interest and awareness. Our data show that entertainment, while increasing interest, can hurt purchase intent, especially if it appears before the brand, and can help purchase intent, when it occurs after the brand. It turns out, we conclude, that David Ogilvy, celebrated adman from the agency Ogilvy and Mather, was right all along: both in 1963, when he claimed that the advertiser should "resist the temptation to entertain" the viewer, and again in 1985 when he claimed that entertainment can sell. Now we can see more clearly how to strike this balance. 


\section{REFERENCES}

Aaker, D. A. and D. E. Bruzonne. 1981. Viewer Perceptions of Prime-Time Television Advertising. Journal of Advertising Research 21(October) 15-23.

Advertising Age. 2008. How Commercial Ratings Changed The \$70B TV Market. by Claire Atkinson, accessed on July 2013 at http://gaia.adage.com/images/random/0908/Commercial-Ratings\%20White\%20Paper.pdf.

Amabile, T. M. 1996. Creativity in Context. Westview Press, Boulder, CO

Armstrong, J. S. 2010. Persuasive Advertising. Palgrave Macmillan, New York, NY.

Ang, S. H., Lee, Y. H., \& Leong, S. M. 2007. The ad creativity cube: conceptualization and initial validation. Journal of the Academy of Marketing Science, 35(2), 220-232

Baumgartner, H., M. Sujan, and D. Padgett. 1997. Patterns of Affective Reactions to Advertisements: The Integration of MTM Responses into Overall Judgments. Journal of Marketing Research 34(2) 219-32.

Belch, G. E., M. A. Belch. 2007. Advertising and Promotion: An Integrated Marketing Communications Perspective.7th ed. McGraw-Hill, New York, NY.

Bryant, J., R. Hezel, and D. Zillmann. 1979. Humor in children's educational television. Communication Education 28(1) 49-59.

Bryce, W. J., R. F. Yalch. 1993. Hearing versus seeing: A comparison of learning of spoken and pictorial information in television advertising. J. Current Issues Res. Advertising 15(1) 1-20.

Chandon, P., W. J. Hutchinson, E. T. Bradlow, and S.H. Young. 2007. Measuring the Value of Point-ofPurchase Marketing with Commercial Eye-Tracking Data. M. Wedel and R. Pieters, eds. Visual Marketing. Lawrence Erlbaum, New York, NY, 225-59.

CNN Money. 2007. The Problem with TV ads. by Paul R. La Monica, accessed on May 2012 at http://money.cnn.com/2007/03/21/commentary/mediabiz/index.htm.

Cohen, I., N. Sebe, A. Garg, L. Chen, and T. Huang. 2003. Facial Expression Recognition from Video Sequences: Temporal and Static Modeling. Computer Vision and Image Understanding 91(1) 160-87.

Deighton, J., D. Romer and J. McQueen. 1989. Using Drama to Persuade. J. of Cons. Res. 16(3) 335-43.

Eisend, M. 2011. How humor in advertising works: A meta-analytic test of alternative models. J. of the Acad. Mark. Sci 37 191-203.

Eisend, M. 2009. meta-analysis of humor in advertising. Marketing Letters 22(2) 115-32.

Fitzsimons, G. J. and V. G. Morwitz. 1996. The Effect of Measuring Intent on Brand-Level Purchase Behavior. Journal of Consumer Research 23(1) 1-11.

Greene, W. H. 2008. Econometric analysis. $6^{\text {th }}$ ed., Prentice Hall, Upper Saddle River, NJ.

Gulas, C. S., M. G. Weinberger. 2006. Humor in Advertising: A Comprehensive Analysis. M.E.Sharpe, Armonk, NY.

Hutchinson, J. W., W. A. Kamakura, J. G. Lynch Jr. 2000. Unobserved heterogeneity as an alternative explanation for "reversal" effects in behavioral research. Journal of Consumer Research 27(3) 324-44.

Janiszewski, C. and L. Warlop. 1993. The Influence of Classical Conditioning Procedures on Subsequent Attention to the Conditioned Brand. Journal of Consumer Research 20(3), 171-89.

Keller, K. L. 1987. Memory Factors in Advertising: The Effect of Advertising Retrieval Cues on Brand Evaluations. Journal of Consumer Research 14(December) 316-33.

Kover, A. J., S. M. Goldberg and W. L. James. 1995. Creativity vs. effectiveness? An integrating classification for advertising. Journal of Advertising Research 35 (November) 29-40.

Krishnan, K. and D. Chakravarti. 2003. A Process Analysis of the Effects of Humorous Advertising Executions on Brand Claims Memory. Journal of Consumer Psychology 13(3) 230-245. 
MacKenzie, S. B., R. J. Lutz, G. E. Belch. 1986. The Role of Attitude Toward the Ad as a Mediator of Advertising Effectiveness: A Test of Competing Explanations. J. of Marketing Res. 23(May) 130-43.

McDuff, D. J., R. El Kaliouby, R. W. Picard. 2012. Crowdsourcing Facial Responses to Online Videos. IEEE Transactions on Affective Computing, 3(4):456-468, 2012.

McDuff, D. J., R. El Kaliouby, T. Senechal, M. Amr, J. F. Cohn, R. Picard. 2013. Affectiva-MIT Facial Expression Dataset (AM-FED): Naturalistic and Spontaneous Facial Expressions Collected In-theWild. Accessed on August 2013 at http://affect.media.mit.edu/pdfs/13.McDuff-etal-AMFED.pdf

Mitchell, A. A., J. C. Olson. 1981. Are Product Attribute Beliefs the Only Mediator of Advertising Effects on Brand Attitude? Journal of Marketing Research 18(August) 318-32.

Nielsen. 2012. Effective Ads Marry Message with Impact. Accessed on August 2013 at http://www.nielsen.com/us/en/newswire/2012/effective-ads-marry-message-with-impact.html.

Pervin, L. A., O. P. John. 1999. Handbook of Personality: Theory and Research. $2^{\text {nd }}$ ed. Guilford Press, New York, NY.

Pieters, R., M. Wedel. 2012. Ad Gist:Ad Communication in a Single Eye Fixation. Mark. Sci 31(1) 59-73. Reinartz, W. and P. Saffert. 2013. Creativity in Advertising: When It Works and When It Doesn’t.

Harvard Business Review June 3-8.

Resnik, A. and B. L. Stern. 1977. An Analysis of Information Content in Television Advertising. Journal of Marketing, 41 (1) 50-53.

Rutz, O. J., M. Trusov. 2011. Zooming In on Paid Search Ads: An Individual-level Model Calibrated on Aggregated Data. Marketing Science 30(5) 789-800.

Smith, R. E., MacKenzie, S. B., Yang, X., Buchholz, L. M., \& Darley, W. K. 2007. Modeling the determinants and effects of creativity in advertising. Marketing Science, 26(6), 819-833

Sternthal, B., C. S. Craig. 1973. Humor in Advertising. Journal of Marketing 37(3) 12-8.

Tellis, G. J. 1998. Advertising and Sales Promotion Strategy, Addison-Wesley, Reading, MA.

Tellis, G. J. 2004. Effective Advertising. Sage Publications, Thousand Oaks, CA.

Teixeira, T. S., H. Stipp. 2013. Optimizing the Amount of Entertainment in Advertising: What's So Funny about Tracking Reactions to Humor? Journal of Advertising Research 53(3) 286-96.

Teixeira, T., M. Wedel, R. Pieters. 2010. Moment-to-moment Optimal Branding in TV Commercials: Preventing Avoidance by Pulsing. Marketing Science 29(5) 783-804.

Teixeira, T., M. Wedel, R. Pieters. 2012. Emotion-induced engagement in internet video ads. Journal of Marketing Research 49(2) 144-159.

Voss, K. E., E. R. Spangenberg, B. Grohmann. 2003. Measuring the Hedonic and Utilitarian Dimensions of Consumer Attitude. Journal of Marketing Research 40(August) 310-20.

West, D. C., A. J. Kover and A. Caruana. 2008. Practitioner and customer views of advertising creativity: Same concept, different meaning?. Journal of Advertising 37(4) 35-46.

White, A., and Smith, B. L. 2001. Assessing advertising creativity using the creative product semantic scale. Journal of Advertising Research, 41(6), 27-34

Woltman Elpers, J. L. C. M., M. Wedel, R. G. M. Pieters. 2003. Why Do Consumers Stop Watching TV Commercials? Two Experiments on the Influence of Moment-to-Moment Entertainment and Information Value. Journal of Marketing Research 40(4) 437-53.

Woltman Elpers, J. L.C.M., A. Mukherjee, W. D. Hoyer. 2004. Humor in television advertising: A moment-to-moment analysis. Journal of Consumer Research 31(3) 592-8.

Yang, X., R. E. Smith. 2009. Beyond Attention Effects: Modeling the Persuasive and Emotional Effects of Advertising Creativity. Marketing Science 28(5) 935-49. 
TABLE 1

EXAMPLES OF POSITIVE ENTERTAINMENT IN SELECTED ADSVERTISEMENTS

\begin{tabular}{|c|c|c|c|c|}
\hline $\begin{array}{c}\text { Brand } \\
\text { Ad }\end{array}$ & $\begin{array}{c}\text { Mountain Dew } \\
\text { Abe Lincoln }\end{array}$ & $\begin{array}{c}\text { Cadbury } \\
\text { Fish-Spots Vs Stripes }\end{array}$ & $\begin{array}{c}\text { Ten Cane Rum } \\
\text { Disco Beach }\end{array}$ & $\begin{array}{c}\text { Coca-Cola } \\
\text { Sleepwalker }\end{array}$ \\
\hline $\begin{array}{c}\text { Example of } \\
\text { entertainment }\end{array}$ & Humor & Visual imagery & Upbeat music & Creative story \\
\hline Snapshot of ad & S & & &
\end{tabular}

TABLE 2

SURVEY MEASUMENTS AND FORMAT OF COLLECTION

\begin{tabular}{|l|l|l|l|}
\hline Measure & Type & Question & Type \\
\hline Purchase Intent & $\begin{array}{l}\text { Dependent } \\
\text { variable }\end{array}$ & $\begin{array}{l}\text { How likely are you to purchase this } \\
\text { brand? }\end{array}$ & $\begin{array}{l}\text { 11-point scale, anchored by } \\
\text { 'Not at all likely' to 'Very } \\
\text { likely' }\end{array}$ \\
\hline Ad Familiarity & Control & $\begin{array}{l}\text { Have you ever seen this ad before (this } \\
\text { study)? }\end{array}$ & Binary, 'Yes' or 'No' \\
\hline Age & Control & What is your age? & $\begin{array}{l}\text { 13 categories between 'less } \\
\text { than 18' and 'more than 50' }\end{array}$ \\
\hline Gender & Control & What is your gender? & Binary, 'Female' or 'Male' \\
\hline Extraversion & Control & How extroverted are you? & $\begin{array}{l}\text { 5-point scale, anchored by } \\
\text { 'Not at all' to 'Extremely' }\end{array}$ \\
\hline $\begin{array}{l}\text { Category } \\
\text { Frequency }\end{array}$ & Control & $\begin{array}{l}\text { How often do you PURCHASE or } \\
\text { CONSUME the following product } \\
\text { categories? }\end{array}$ & $\begin{array}{l}\text { 5-point scale, anchored by } \\
\text { 'Never' to 'Very often' }\end{array}$ \\
\hline $\begin{array}{l}\text { Category } \\
\text { Interest }\end{array}$ & Control & $\begin{array}{l}\text { How INTERESTED are you in the } \\
\text { brands in the following product } \\
\text { categories? }\end{array}$ & $\begin{array}{l}\text { 5-point scale, anchored by } \\
\text { 'Not at all interested' to 'Very } \\
\text { interested' }\end{array}$ \\
\hline $\begin{array}{l}\text { Category } \\
\text { Knowledge }\end{array}$ & Control & $\begin{array}{l}\text { How KNOWLEDGEABLE are you } \\
\text { about the brands in the following } \\
\text { product categories? }\end{array}$ & $\begin{array}{l}\text { 5-point scale, anchored by } \\
\text { 'Not at all knowledgeable' to } \\
\text { 'Very knowledgeable' }\end{array}$ \\
\hline $\begin{array}{l}\text { Prior Brand } \\
\text { Consideration }\end{array}$ & Control \\
\hline $\begin{array}{l}\text { Prior Brand } \\
\text { Entertainment }\end{array}$ & Control & $\begin{array}{l}\text { How muchasing this brand? } \\
\text { do you consider these brands to be? }\end{array}$ & $\begin{array}{l}\text { Binary, 'No' or 'Yes' } \\
\text { to 'Very fun and entertaining' }\end{array}$ \\
\hline
\end{tabular}


TABLE 3

SUMMARY STATISTICS OF THE FIELD DATA

\begin{tabular}{|c|c|c|c|c|c|c|}
\hline Variable & Variation unit & $\mathrm{N}^{*}$ & Mean & Std. Dev. & Minimum & Maximum \\
\hline Viewing Interest & ad $\mathrm{x}$ individual & 3487 & $81.2 \%$ & $39.1 \%$ & $0 \%$ & $100 \%$ \\
\hline Purchase Intention & ad $\mathrm{x}$ individual & 3487 & 4.4 & 2.9 & 0 & 10 \\
\hline \multicolumn{7}{|l|}{ Content: } \\
\hline Entertainment & ad $\mathrm{x}$ individual & 3487 & $23.3 \%$ & $15.9 \%$ & $0 \%$ & $94.1 \%$ \\
\hline Pre-brand entertainment & ad $\mathrm{x}$ individual & 3487 & $20.6 \%$ & $16.6 \%$ & $0 \%$ & $98.0 \%$ \\
\hline Post-brand entertainment & $\mathrm{ad} \mathrm{x}$ individual & 3487 & $24.4 \%$ & $19.4 \%$ & $0 \%$ & $98.6 \%$ \\
\hline Time to First brand (seconds) & ad & 82 & 22.6 & 20.9 & 0 & 85 \\
\hline Ad length (seconds) & ad & 82 & 40.0 & 19.3 & 14 & 90 \\
\hline \multicolumn{7}{|l|}{ Category: } \\
\hline Frequency Beverage & individual & 178 & 3.8 & 1.1 & 1 & 5 \\
\hline Frequency Alcohol & individual & 178 & 2.9 & 1.2 & 1 & 5 \\
\hline Frequency Confectionary & individual & 178 & 3.1 & 1.1 & 1 & 5 \\
\hline Knowledge Beverage & individual & 178 & 3.5 & 1.0 & 1 & 5 \\
\hline Knowledge Alcohol & individual & 178 & 2.9 & 1.3 & 1 & 5 \\
\hline Knowledge Confectionary & individual & 178 & 3.5 & 1.0 & 1 & 5 \\
\hline Interest Beverage & individual & 178 & 3.3 & 1.2 & 1 & 5 \\
\hline Interest Alcohol & individual & 178 & 3.1 & 1.4 & 1 & 5 \\
\hline Interest Confectionary & individual & 178 & 3.4 & 1.2 & 1 & 5 \\
\hline \multicolumn{7}{|l|}{ Individual: } \\
\hline Participant age (years) & individual & 178 & 26 & 9 & 21 & $>50$ \\
\hline Participant gender $($ male $=1)$ & individual & 178 & $37.8 \%$ & $48.5 \%$ & 0 & 1 \\
\hline Extraversion score (5-pt) & individual & 178 & 2.9 & 1.1 & 1 & 5 \\
\hline Ad familiarity (familiar=1) & $\mathrm{ad} \mathrm{x}$ individual & 3487 & $13.7 \%$ & $34.4 \%$ & 0 & 1 \\
\hline Prior Brand Consideration & $\mathrm{ad} \mathrm{x}$ individual & 3487 & $24.6 \%$ & $43.1 \%$ & 0 & 1 \\
\hline Prior Brand Entertainment & ad $\mathrm{x}$ individual & 3487 & 3.3 & 1.2 & 1 & 5 \\
\hline
\end{tabular}

Note- Entertainment measures are summary statistics of the average intensity of expressions of smile on a 0 to $100 \%$ scale across ad, time and individuals. *Summary statistics are provided for the actual data used in the model. 
TABLE 4

EFFECTS OF ENTERTAINMENT CONTENT ON VIEWING INTEREST AND PURCHASE INTENT

\begin{tabular}{|c|c|c|c|c|c|c|c|c|c|c|c|c|}
\hline \multirow[t]{2}{*}{ Parameter } & \multicolumn{6}{|c|}{ Viewing Interest } & \multicolumn{6}{|c|}{ Purchase Intent } \\
\hline & Mean & SE & \multicolumn{4}{|c|}{ PPD } & Mean & SE & $5 \%$ & \multicolumn{2}{|c|}{ PPD } & $95 \%$ \\
\hline Intercept & -0.644 & 0.268 & -1.081 & -0.970 & -0.312 & -0.208 & -0.168 & 0.110 & -0.343 & -0.309 & -0.023 & 0.016 \\
\hline Interest & & & & & & & 0.220 & 0.060 & 0.117 & 0.138 & 0.295 & 0.319 \\
\hline Entertainment & 0.987 & 0.487 & 0.204 & 0.351 & 1.630 & 1.794 & 0.905 & 0.346 & 0.353 & 0.467 & 1.354 & 1.491 \\
\hline Entertainment $^{2}$ & $* 0.000$ & 0.000 & 0.000 & 0.000 & 0.000 & 0.000 & -1.014 & 0.508 & -1.837 & -1.653 & -0.370 & -0.166 \\
\hline Control variables: & & & & & & & & & & & & \\
\hline Information & 0.046 & 0.031 & -0.003 & 0.005 & 0.088 & 0.097 & 0.040 & 0.019 & 0.008 & 0.016 & 0.065 & 0.073 \\
\hline Creativity & -0.013 & 0.026 & -0.055 & -0.047 & 0.021 & 0.031 & 0.054 & 0.017 & 0.025 & 0.031 & 0.076 & 0.081 \\
\hline Prior Brand Consideration & 0.151 & 0.068 & 0.035 & 0.070 & 0.239 & 0.262 & 0.577 & 0.043 & 0.505 & 0.522 & 0.631 & 0.647 \\
\hline Prior Brand Entertainment & 0.083 & 0.023 & 0.045 & 0.052 & 0.113 & 0.121 & & & & & & \\
\hline Involvement & 0.060 & 0.026 & 0.014 & 0.025 & 0.094 & 0.101 & 0.176 & 0.017 & 0.148 & 0.155 & 0.198 & 0.205 \\
\hline Extraversion & 0.004 & 0.025 & -0.038 & -0.028 & 0.036 & 0.046 & 0.062 & 0.013 & 0.040 & 0.043 & 0.079 & 0.084 \\
\hline Participant age & 0.085 & 0.011 & 0.068 & 0.071 & 0.098 & 0.102 & 0.022 & 0.005 & 0.015 & 0.016 & 0.030 & 0.032 \\
\hline Gender $($ male $=1$ ) & -0.170 & 0.055 & -0.257 & -0.239 & -0.102 & -0.078 & 0.061 & 0.028 & 0.019 & 0.025 & 0.102 & 0.110 \\
\hline Ad familiarity (familiar=1) & -0.529 & 0.078 & -0.404 & -0.433 & -0.631 & -0.657 & 0.166 & 0.027 & 0.220 & 0.206 & 0.131 & 0.126 \\
\hline Ad length (seconds) & -0.011 & 0.002 & -0.014 & -0.013 & -0.009 & -0.008 & -0.002 & 0.001 & -0.003 & -0.003 & -0.001 & 0.000 \\
\hline Time to First brand & 0.002 & 0.001 & -0.001 & 0.000 & 0.004 & 0.004 & 0.002 & 0.002 & -0.001 & 0.000 & 0.004 & 0.004 \\
\hline Variance of error term & 1.000 & 0.000 & 1.000 & 1.000 & 1.000 & 1.000 & 0.449 & 0.011 & 0.431 & 0.435 & 0.463 & 0.468 \\
\hline Covariance of error term & -0.004 & 0.021 & -0.038 & -0.031 & 0.024 & 0.030 & -0.004 & 0.021 & -0.038 & -0.031 & 0.024 & 0.030 \\
\hline
\end{tabular}

Note - PPD stands for Percentile of Posterior Distribution. *Forced to 0 due to insignificance at the $95 \%$ posterior interval (mean=0.681, $2.5 \%$ PPD= -0.842 and $97.5 \%$ PPD $=2.344$ ). Bold stands for one-tailed significance at the $95 \%$ posterior interval. Italics stands for significant at the $90 \%$ posterior interval. 
TABLE 5

EFFECTS OF LEVEL AND AMOUNT OF ENTERTAINMENT ON PURCHASE INTENT

\begin{tabular}{|c|c|c|c|c|c|c|c|c|c|c|c|c|}
\hline \multirow{4}{*}{\begin{tabular}{|l|} 
Parameter \\
\\
Intercept
\end{tabular}} & \multicolumn{12}{|c|}{ Purchase Intent } \\
\hline & \multicolumn{6}{|c|}{ Level of Entertainment } & \multicolumn{6}{|c|}{ Amount of Entertainment } \\
\hline & \multirow{2}{*}{$\begin{array}{c}\text { Mean } \\
-0.160\end{array}$} & \multirow{2}{*}{\begin{tabular}{l|}
$\mathrm{SE}$ \\
0.180
\end{tabular}} & \multirow{2}{*}{\begin{tabular}{|c|}
$5 \%$ \\
-0.472
\end{tabular}} & \multicolumn{3}{|c|}{$\begin{array}{c}10 \% \quad 90 \% \\
\text { PPD } \\
\end{array}$} & \multirow{2}{*}{\begin{tabular}{l|} 
Mean \\
-0.225
\end{tabular}} & \multirow{2}{*}{$\begin{array}{l}\text { SE } \\
0.185\end{array}$} & \multicolumn{4}{|c|}{$\begin{array}{c}10 \% \quad 90 \% \\
\text { PPD }\end{array}$} \\
\hline & & & & -0.398 & 0.072 & 0.129 & & & -0.520 & -0.475 & 0.012 & 0.072 \\
\hline Interest & 0.191 & 0.068 & 0.076 & 0.105 & 0.276 & 0.300 & 0.257 & 0.060 & 0.161 & 0.180 & 0.333 & 0.353 \\
\hline Pre-brand-associated entertainment & 0.312 & 0.338 & -0.267 & -0.126 & 0.704 & 0.853 & 1.017 & 0.483 & 0.224 & 0.402 & 1.599 & 1.759 \\
\hline Pre-brand-associated entertainment ${ }^{2}$ & -0.800 & 0.551 & -1.682 & -1.512 & -0.098 & 0.053 & -1.316 & 0.746 & -2.487 & -2.244 & -0.441 & -0.098 \\
\hline Post-Brand-associated entertainment & 0.698 & 0.337 & 0.128 & 0.248 & 1.120 & 1.210 & 0.989 & 0.443 & 0.259 & 0.426 & 1.577 & 1.679 \\
\hline Post-Brand-associated entertainment ${ }^{2}$ & -0.256 & 0.457 & -0.962 & -0.828 & 0.329 & 0.498 & -0.837 & 0.648 & -1.898 & -1.668 & -0.001 & 0.207 \\
\hline \multicolumn{13}{|l|}{ Control variables: } \\
\hline Brand association & 0.039 & 0.033 & -0.011 & -0.001 & 0.082 & 0.092 & 0.034 & 0.033 & -0.019 & -0.007 & 0.077 & 0.086 \\
\hline Information & 0.020 & 0.025 & -0.020 & -0.012 & 0.052 & 0.064 & 0.023 & 0.026 & -0.020 & -0.013 & 0.054 & 0.063 \\
\hline Creativity & 0.023 & 0.021 & -0.008 & -0.003 & 0.050 & 0.059 & 0.029 & 0.019 & -0.002 & 0.004 & 0.054 & 0.060 \\
\hline Prior Brand Consideration & 0.564 & 0.042 & 0.495 & 0.511 & 0.620 & 0.634 & 0.569 & 0.043 & 0.498 & 0.516 & 0.623 & 0.640 \\
\hline Involvement & 0.178 & 0.018 & 0.148 & 0.156 & 0.200 & 0.207 & 0.177 & 0.017 & 0.150 & 0.154 & 0.200 & 0.206 \\
\hline Extraversion & 0.065 & 0.017 & 0.037 & 0.044 & 0.087 & 0.094 & 0.067 & 0.017 & 0.038 & 0.045 & 0.089 & 0.096 \\
\hline Participant age & 0.019 & 0.006 & 0.009 & 0.012 & 0.026 & 0.028 & 0.018 & 0.006 & 0.008 & 0.011 & 0.025 & 0.028 \\
\hline Gender (male =1) & 0.063 & 0.036 & 0.000 & 0.016 & 0.109 & 0.125 & 0.060 & 0.037 & 0.000 & 0.014 & 0.108 & 0.121 \\
\hline Ad familiarity (familiar=1) & 0.201 & 0.052 & 0.284 & 0.264 & 0.127 & 0.114 & 0.200 & 0.056 & 0.292 & 0.270 & 0.129 & 0.105 \\
\hline Ad length (seconds) & 0.001 & 0.001 & -0.001 & 0.000 & 0.002 & 0.003 & 0.001 & 0.001 & -0.001 & -0.001 & 0.003 & 0.003 \\
\hline Time to First brand & 0.000 & 0.001 & -0.002 & -0.002 & 0.001 & 0.002 & 0.000 & 0.002 & -0.003 & -0.002 & 0.003 & 0.003 \\
\hline Variance of error term & 0.455 & 0.011 & 0.435 & 0.440 & 0.469 & 0.474 & 0.459 & 0.012 & 0.439 & 0.443 & 0.473 & 0.478 \\
\hline Covariance of error term & -0.008 & 0.020 & -0.041 & -0.034 & 0.017 & 0.025 & -0.012 & 0.021 & -0.047 & -0.040 & 0.015 & 0.023 \\
\hline
\end{tabular}

Note - PPD stands for Percentile of Posterior Distribution. Bold stands for one-tailed significance at 95\% PPD. Italics stands for significant at 90\% PPD. 
FIGURE 1

CONCEPTUAL MODEL OF THE ROLE OF ENTERTAINMENT IN THE PURCHASE FUNNEL

(A)

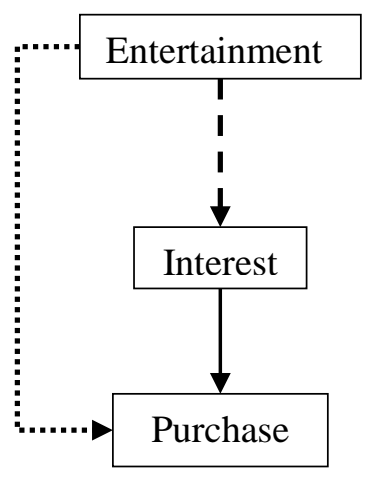

(B)

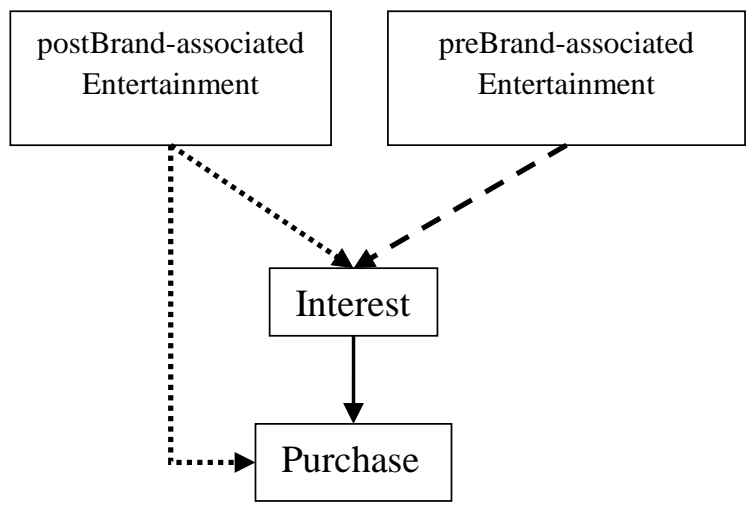

Legend

$-\rightarrow$ Impact through Ad Attractiveness $\quad \cdots \cdots . . . \rightarrow$ Impact through Ad Persuasiveness

FIGURE 2

SAMPLE OF FACIAL IMAGES COLLECTED OVER THE WEB

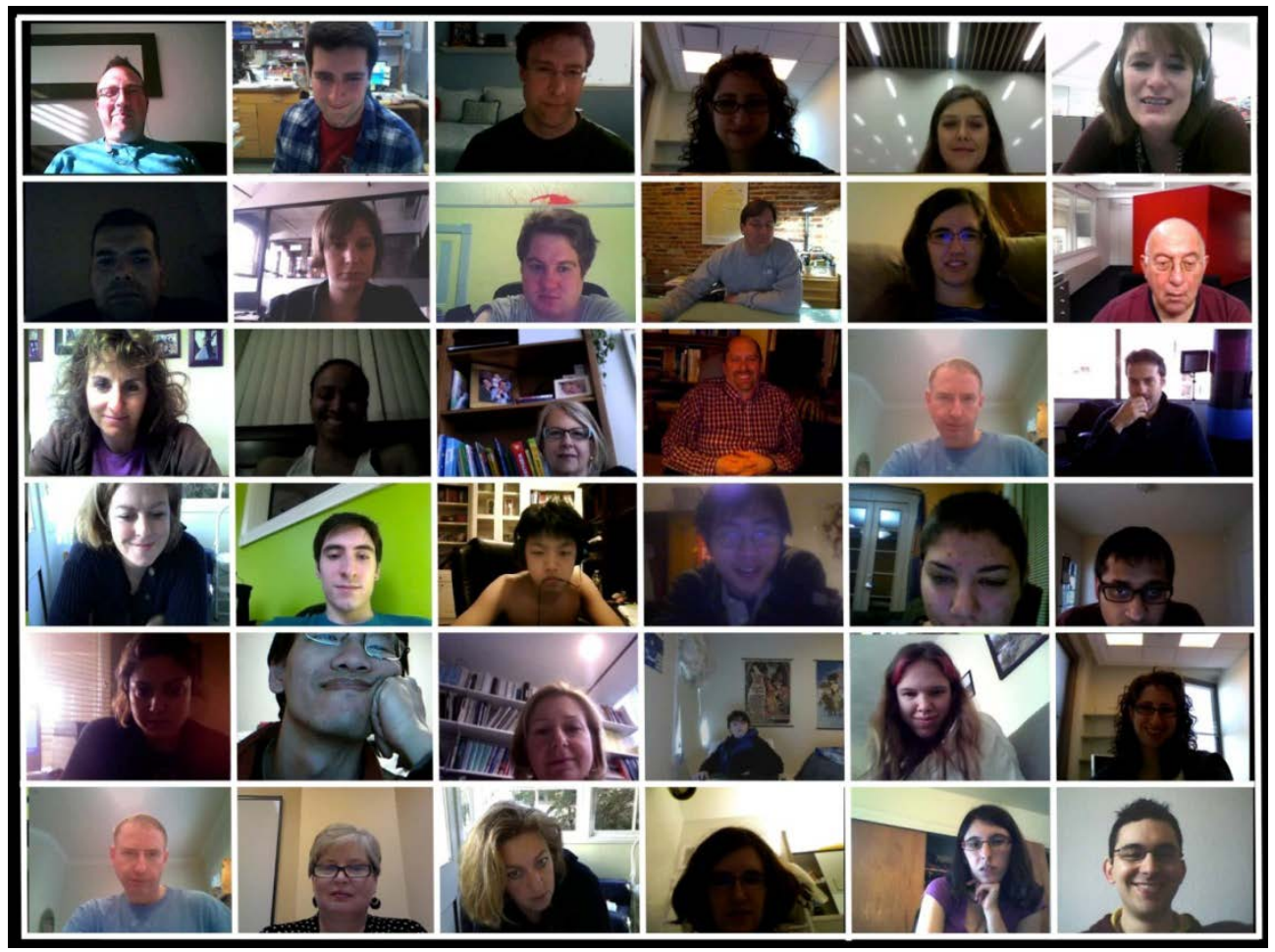

Note: Due to a series of factors (e.g., low lighting, cropped face, hands covering face) not all data collected was used. 
FIGURE 3

VIEWING INTEREST AND PURCHASE INTENT BY LEVEL OF ENTERTAINMENT

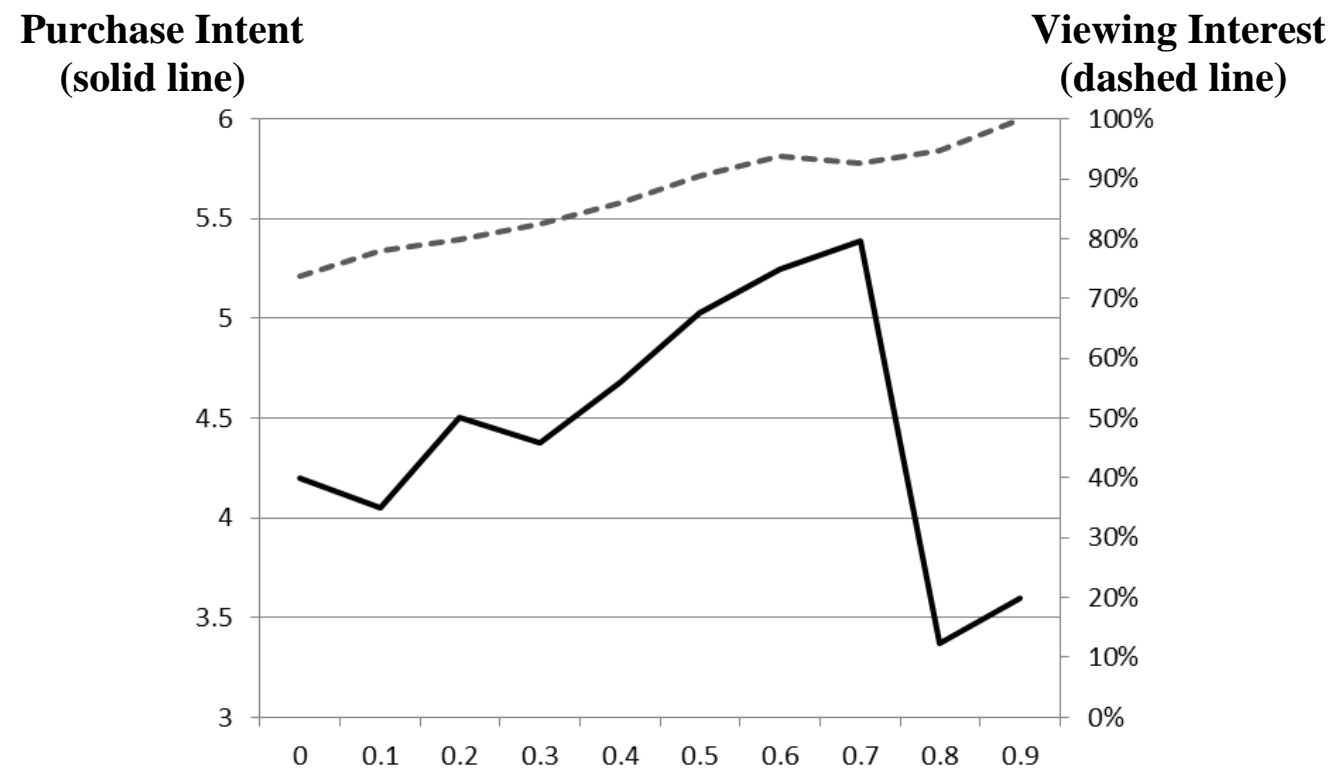

Decile of Entertainment level

Note - Measures calculated by computing the average smile intensities across the 178 participants and 82 ads, ordering it into decile bins, and computing average interest and purchase intent for each bin.

FIGURE 4

PATTERN OF INFLUENCE OF ENTERTAINMENT ON CONSUMER DECISION STAGE

Viewing Interest (utility)

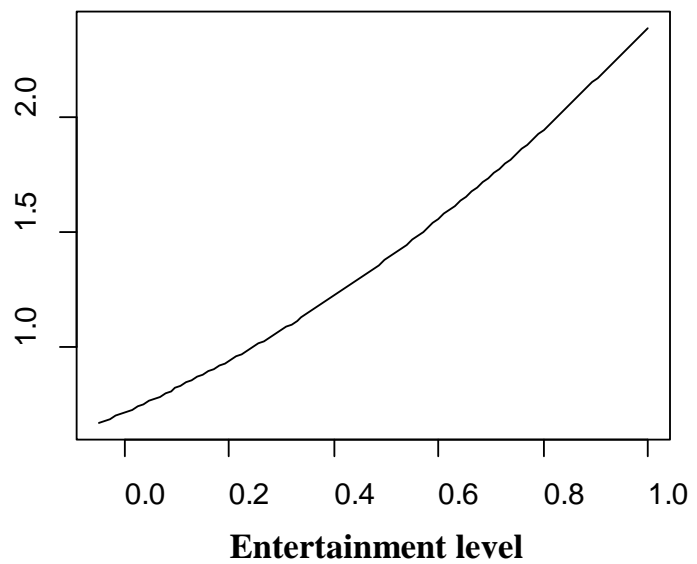

Purchase Intent

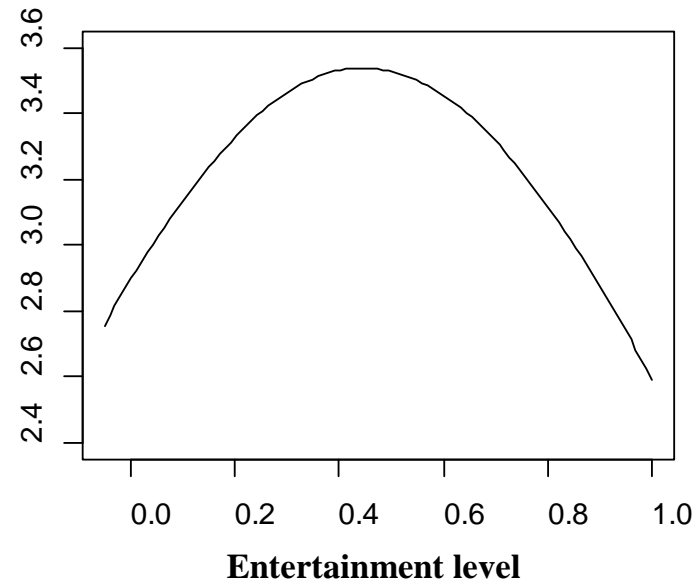

Note - Curves are plotted using the average value of the covariates and mean parameter estimates of the model for all other (non-entertainment) covariates. The average Purchase Intent range across all 82 ads is [2.5; 7.0]. The estimated range of Purchase Intent variation purely due to differences in Entertainment level across ads is $21 \%$. 
FIGURE 5

PURCHASE INTENT BY LOCATION OF BRAND AND LEVEL OF ENTERTAINMENT

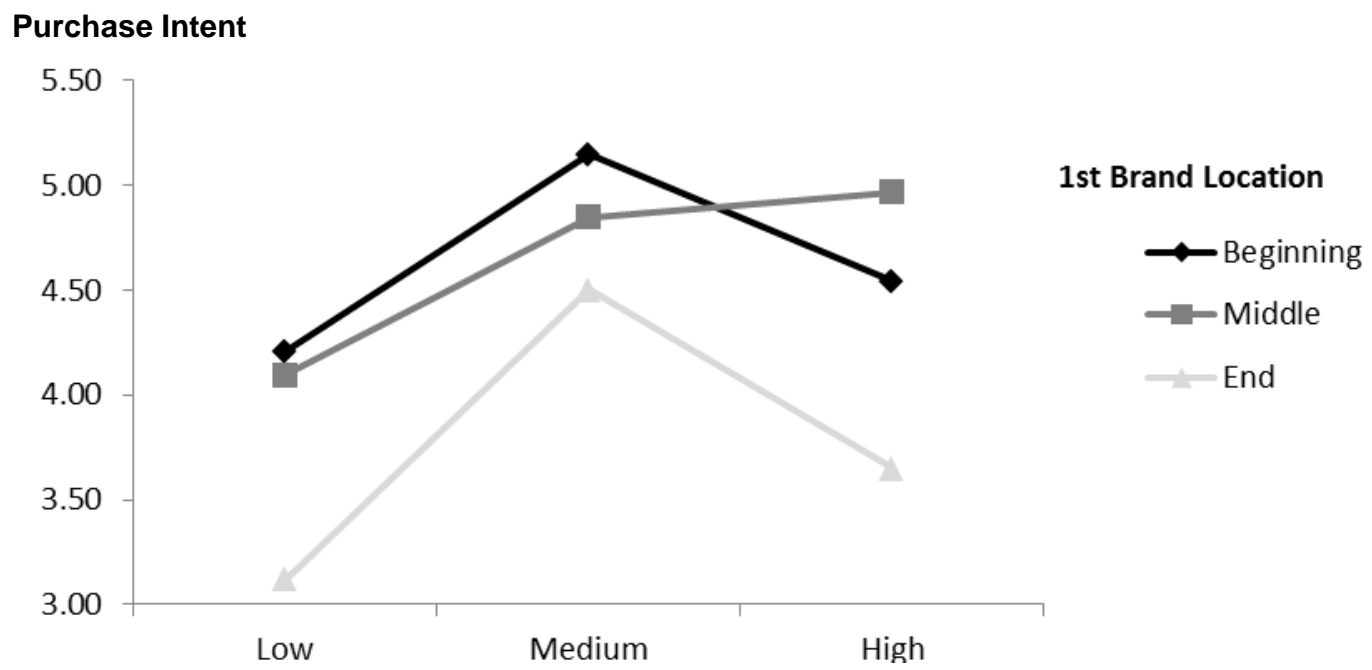

Average entertainment level

FIGURE 6

PATTERN OF INFLUENCE OF ENTERTAINMENT TYPE ON PURCHASE INTENT

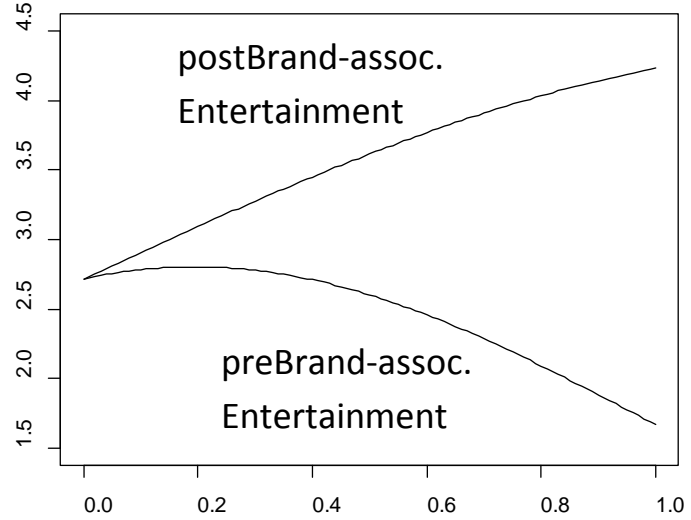

Entertainment Level

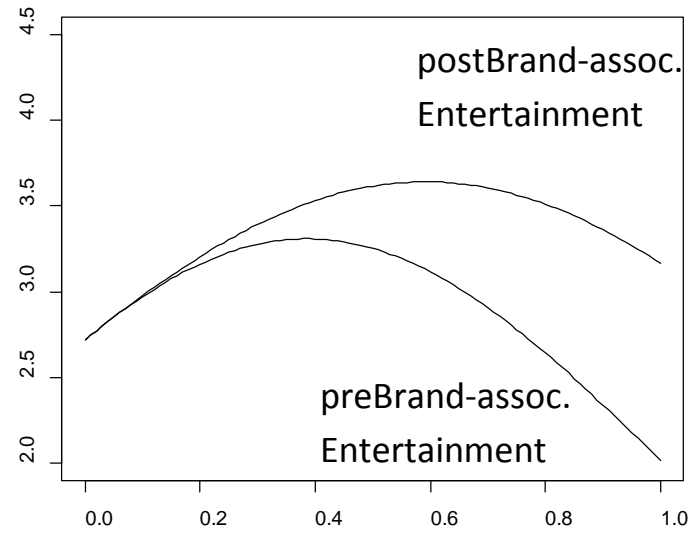

Entertainment Amount

Note - Curves are plotted using the average value of the covariates and mean parameter estimates of the model for all other (non-entertainment) covariates. 
APPENDIX 1

AVERAGE VIEWS AND ENTERTAINMENT LEVELS FOR EACH AD

\begin{tabular}{|c|c|c|c|c|c|c|}
\hline \multirow[b]{2}{*}{ Category } & \multirow[b]{2}{*}{ Brand } & \multirow[b]{2}{*}{ Ad title } & \multicolumn{2}{|r|}{ Views } & \multicolumn{2}{|c|}{ Entertainment } \\
\hline & & & Shown & $\%$ Completed & Average & S.d. \\
\hline Beverage & Mountain Dew & Abe Lincoln & 7 & $86 \%$ & 0.371 & 0.189 \\
\hline Alcohol & Bud Light & Clothing Drive & 64 & $69 \%$ & 0.314 & 0.172 \\
\hline Beverage & Pepsi Max & First Date & 10 & $90 \%$ & 0.310 & 0.178 \\
\hline Beverage & Cumberland Farms & Heaven & 28 & $86 \%$ & 0.307 & 0.218 \\
\hline Beverage & Cravendale & Toe Tapping & 31 & $87 \%$ & 0.306 & 0.169 \\
\hline Confectionary & Cadbury & Dancing Eyebrows & 87 & $86 \%$ & 0.301 & 0.171 \\
\hline Confectionary & Skittles & Skittles Touch Cat & 34 & $79 \%$ & 0.298 & 0.169 \\
\hline Beverage & Pepsi Max & Nod & 12 & $83 \%$ & 0.292 & 0.211 \\
\hline Beverage & Cravendale & Cats with Thumbs & 26 & $73 \%$ & 0.287 & 0.209 \\
\hline Confectionary & Snickers & Party & 38 & $84 \%$ & 0.287 & 0.138 \\
\hline Alcohol & Ten Cane Rum & Cool Breeze & 21 & $62 \%$ & 0.280 & 0.197 \\
\hline Beverage & Snapple & Bottles & 24 & $88 \%$ & 0.280 & 0.171 \\
\hline Confectionary & Starburst & First Date & 50 & $82 \%$ & 0.280 & 0.147 \\
\hline Confectionary & Trident & Party Blower & 95 & $94 \%$ & 0.276 & 0.159 \\
\hline Beverage & Pepsi Max & Love Hurts & 18 & $83 \%$ & 0.276 & 0.183 \\
\hline Beverage & Pepsi & Penguin & 29 & $97 \%$ & 0.273 & 0.190 \\
\hline Beverage & Pepsi & Will Arnett's Super Bowl & 17 & $88 \%$ & 0.271 & 0.200 \\
\hline Alcohol & Ten Cane Rum & Strategy & 11 & $82 \%$ & 0.271 & 0.188 \\
\hline Confectionary & Skittles & Fly & 42 & $88 \%$ & 0.269 & 0.150 \\
\hline Beverage & Coke Zero & 3D Reenactment & 30 & $73 \%$ & 0.264 & 0.178 \\
\hline Beverage & Mountain Dew & Loaded Yo-Yos & 22 & $91 \%$ & 0.263 & 0.163 \\
\hline Beverage & Sobe & On The Bottle & 31 & $61 \%$ & 0.261 & 0.178 \\
\hline Beverage & Pepsi & Archaeology & 10 & $100 \%$ & 0.260 & 0.121 \\
\hline Alcohol & Ten Cane Rum & Airport & 15 & $87 \%$ & 0.256 & 0.139 \\
\hline Confectionary & Starburst & Interview & 42 & $81 \%$ & 0.255 & 0.193 \\
\hline Confectionary & Trident & Copy Cat & 78 & $88 \%$ & 0.254 & 0.172 \\
\hline Beverage & Coke Zero & Slap & 29 & $90 \%$ & 0.252 & 0.140 \\
\hline Beverage & Coca & Cola-Sleepwalker & 34 & $88 \%$ & 0.250 & 0.173 \\
\hline Confectionary & Stride & Water & 44 & $73 \%$ & 0.249 & 0.163 \\
\hline Beverage & Sun Drop & Drop It & 56 & $80 \%$ & 0.246 & 0.165 \\
\hline Alcohol & Ten Cane Rum & Cocktail Hours & 10 & $90 \%$ & 0.246 & 0.119 \\
\hline Alcohol & Captain Morgan & Captain Improve & 97 & $87 \%$ & 0.245 & 0.174 \\
\hline Confectionary & Snickers & Betty White & 50 & $66 \%$ & 0.245 & 0.178 \\
\hline Confectionary & Dentyne & Blog Smog & 81 & $72 \%$ & 0.244 & 0.171 \\
\hline Confectionary & $M \& M s$ & Listen Buddy & 76 & $80 \%$ & 0.244 & 0.164 \\
\hline Alcohol & Bud Light & Pimp Your Ride & 54 & $80 \%$ & 0.244 & 0.164 \\
\hline Alcohol & Bud Light Lime & In The Can & 175 & $86 \%$ & 0.244 & 0.168 \\
\hline Alcohol & Dos Equis & Snow Monkeys & 91 & $90 \%$ & 0.244 & 0.152 \\
\hline Beverage & Muscle Milk & Chet & 34 & $94 \%$ & 0.242 & 0.146 \\
\hline
\end{tabular}




\begin{tabular}{|c|c|c|c|c|c|c|}
\hline \multirow{2}{*}{$\begin{array}{l}\text { (continued) } \\
\text { Category }\end{array}$} & \multirow[b]{2}{*}{ Brand } & \multirow[b]{2}{*}{ Ad title } & \multicolumn{2}{|r|}{ Views } & \multicolumn{2}{|c|}{ Entertainment } \\
\hline & & & Shown & $\%$ Completed & Average & S.d. \\
\hline Beverage & Coca & Cola-Border & 23 & $91 \%$ & 0.240 & 0.131 \\
\hline Alcohol & Bud Light & House Keeping & 58 & $86 \%$ & 0.240 & 0.168 \\
\hline Beverage & Lipton Brisk & Ozzy & 22 & $68 \%$ & 0.240 & 0.161 \\
\hline Beverage & Lipton Brisk & Machete & 22 & $73 \%$ & 0.238 & 0.223 \\
\hline Beverage & Diet Pepsi & Recess & 25 & $80 \%$ & 0.236 & 0.124 \\
\hline Beverage & Glaceau Vitamin Water & Carrie Underwood & 32 & $81 \%$ & 0.236 & 0.127 \\
\hline Beverage & Mountain Dew & Lightning 2 & 18 & $94 \%$ & 0.236 & 0.133 \\
\hline Confectionary & Stride & Urn & 47 & $85 \%$ & 0.235 & 0.136 \\
\hline Confectionary & Snickers & Focus Group & 41 & $85 \%$ & 0.234 & 0.176 \\
\hline Confectionary & M\&Ms & Hostages & 99 & $86 \%$ & 0.233 & 0.147 \\
\hline Beverage & Red Bull & Classical Cat & 35 & $89 \%$ & 0.233 & 0.167 \\
\hline Alcohol & Ten Cane Rum & Big World & 13 & $100 \%$ & 0.232 & 0.100 \\
\hline Confectionary & Starburst & Roomies & 45 & $96 \%$ & 0.231 & 0.137 \\
\hline Confectionary & Cadbury & Fish-Spots Vs Stripes & 87 & $72 \%$ & 0.231 & 0.153 \\
\hline Confectionary & Skittles & Fist & 46 & $87 \%$ & 0.231 & 0.155 \\
\hline Beverage & Diet Pepsi & Beach Tweet & 32 & $81 \%$ & 0.229 & 0.159 \\
\hline Beverage & Glaceau Vitamin Water & Frog & 28 & $86 \%$ & 0.226 & 0.134 \\
\hline Beverage & Sobe & Summer Magic & 26 & $96 \%$ & 0.224 & 0.135 \\
\hline Alcohol & Ten Cane Rum & Magic & 18 & $83 \%$ & 0.224 & 0.140 \\
\hline Alcohol & Budweiser & Quittin Time & 49 & $63 \%$ & 0.224 & 0.139 \\
\hline Beverage & Muscle Milk & Katie & 21 & $100 \%$ & 0.224 & 0.189 \\
\hline Confectionary & Dentyne & Bookstore & 95 & $89 \%$ & 0.223 & 0.158 \\
\hline Confectionary & Stride & Chase & 35 & $83 \%$ & 0.222 & 0.139 \\
\hline Beverage & Cumberland Farms & Princess & 29 & $93 \%$ & 0.220 & 0.130 \\
\hline Alcohol & Dos Equis & Ice Fishing & 84 & $69 \%$ & 0.220 & 0.154 \\
\hline Alcohol & Captain Morgan & Dive & 80 & $71 \%$ & 0.217 & 0.118 \\
\hline Alcohol & Ten Cane Rum & Armadillo & 14 & $64 \%$ & 0.214 & 0.152 \\
\hline Alcohol & Budweiser & Wild West (Animated) & 71 & $66 \%$ & 0.213 & 0.148 \\
\hline Confectionary & Stride & Slap & 46 & $74 \%$ & 0.211 & 0.144 \\
\hline Beverage & Red Bull & Poor Luigi & 21 & $86 \%$ & 0.210 & 0.135 \\
\hline Alcohol & Ten Cane Rum & Cannon Ball & 19 & $58 \%$ & 0.208 & 0.141 \\
\hline Beverage & Lipton Brisk & Eminem & 14 & $86 \%$ & 0.206 & 0.147 \\
\hline Confectionary & Skittles & Skittles Park & 53 & $79 \%$ & 0.206 & 0.142 \\
\hline Alcohol & Made in Milan & How Romeo pulls Juliet & 175 & $73 \%$ & 0.204 & 0.138 \\
\hline Alcohol & Ten Cane Rum & Fantasy & 19 & $63 \%$ & 0.197 & 0.136 \\
\hline Confectionary & Starburst & Getaway & 39 & $87 \%$ & 0.195 & 0.125 \\
\hline Alcohol & Budweiser & Jerry & 56 & $79 \%$ & 0.195 & 0.135 \\
\hline Confectionary & Snickers & Logging & 47 & $81 \%$ & 0.192 & 0.140 \\
\hline Alcohol & Ten Cane Rum & Big Day & 12 & $83 \%$ & 0.186 & 0.101 \\
\hline Beverage & Mountain Dew & Bug Zapper & 11 & $73 \%$ & 0.185 & 0.105 \\
\hline Beverage & Snapple & Better Stuff & 32 & $88 \%$ & 0.185 & 0.133 \\
\hline Beverage & Pepsi Max & Catch & 18 & $72 \%$ & 0.181 & 0.149 \\
\hline Alcohol & Ten Cane Rum & Disco Beach & 21 & $57 \%$ & 0.163 & 0.105 \\
\hline
\end{tabular}

